\title{
Article \\ Comparative TCO Analysis of Battery Electric and Hydrogen Fuel Cell Buses for Public Transport System in Small to Midsize Cities
}

\author{
Hanhee Kim ${ }^{1, *}$, Niklas Hartmann ${ }^{1}$, Maxime Zeller ${ }^{2}$, Renato Luise ${ }^{2}$ and Tamer Soylu ${ }^{3}$ \\ 1 Institute of Energy Systems Technology (INES), Offenburg University of Applied Sciences, Badstrasse 24, \\ 77652 Offenburg, Germany; niklas.hartmann@hs-offenburg.de \\ 2 European Institute for Energy Research (EIFERI), Emmy-Noether-Str. 11, 76131 Karlsruhe, Germany; \\ Maxime.Zeller@eifer.uni-karlsruhe.de (M.Z.); Renato.Luise@eifer.uni-karlsruhe.de (R.L.) \\ 3 Regionalverband Mittlerer Oberrhein, Haus der Region, Baumeisterstraße 2, 76137 Karlsruhe, Germany; \\ tamer.soylu@kit.edu \\ * Correspondence: hanhee.kim@hs-offenburg.de
}

check for

updates

Citation: Kim, H.; Hartmann, N.; Zeller, M.; Luise, R.; Soylu, T. Comparative TCO Analysis of Battery Electric and Hydrogen Fuel Cell Buses for Public Transport System in Small to Midsize Cities. Energies 2021, 14, 4384. https://doi.org/10.3390/ en14144384

Academic Editor: James Trevor Hinkley

\section{Received: 27 April 2021}

Accepted: 9 July 2021

Published: 20 July 2021

Publisher's Note: MDPI stays neutral with regard to jurisdictional claims in published maps and institutional affiliations.

Copyright: (c) 2021 by the authors. Licensee MDPI, Basel, Switzerland. This article is an open access article distributed under the terms and conditions of the Creative Commons Attribution (CC BY) license (https:/ / creativecommons.org/licenses/by/ $4.0 /)$.

\begin{abstract}
This paper shows the results of an in-depth techno-economic analysis of the public transport sector in a small to midsize city and its surrounding area. Public battery-electric and hydrogen fuel cell buses are comparatively evaluated by means of a total cost of ownership (TCO) model building on historical data and a projection of market prices. Additionally, a structural analysis of the public transport system of a specific city is performed, assessing best fitting bus lines for the use of electric or hydrogen busses, which is supported by a brief acceptance evaluation of the local citizens. The TCO results for electric buses show a strong cost decrease until the year 2030, reaching 23.5\% lower TCOs compared to the conventional diesel bus. The optimal electric bus charging system will be the opportunity (pantograph) charging infrastructure. However, the opportunity charging method is applicable under the assumption that several buses share the same station and there is a "hotspot" where as many as possible bus lines converge. In the case of electric buses for the year 2020, the parameter which influenced the most on the TCO was the battery cost, opposite to the year 2030 in where the bus body cost and fuel cost parameters are the ones that dominate the TCO, due to the learning rate of the batteries. For $\mathrm{H}_{2}$ buses, finding a hotspot is not crucial because they have a similar range to the diesel ones as well as a similar refueling time. $\mathrm{H}_{2}$ buses until 2030 still have $15.4 \%$ higher TCO than the diesel bus system. Considering the benefits of a hypothetical scaling-up effect of hydrogen infrastructures in the region, the hydrogen cost could drop to $5 € / \mathrm{kg}$. In this case, the overall TCO of the hydrogen solution would drop to a slightly lower TCO than the diesel solution in 2030. Therefore, hydrogen buses can be competitive in small to midsize cities, even with limited routes. For hydrogen buses, the bus body and fuel cost make up a large part of the TCO. Reducing the fuel cost will be an important aspect to reduce the total TCO of the hydrogen bus.
\end{abstract}

Keywords: electric bus; hydrogen bus; zero-emission buses (ZEB); city bus; public transport; total cost of ownership (TCO)

\section{Introduction}

The deployment of battery-electric buses and hydrogen fuel cell buses within the public transportation sector plays an important role in decreasing the exhaust gas emissions of transportation [1]. The introduction of both technologies has accelerated quickly in the last decade, influenced by national energy policies and driven by environmental requirements more than by commercial considerations. With the subsidies from government funding, many cities are increasingly committing to the electrification of their bus fleets [2].

Several studies show positive predictions for the introduction of zero-emission buses [3-6]. One article makes an attempt to simulate the number of zero-emission buses 
(ZEB) in European Union (EU) member countries in two-time horizons: 2025 and 2030 and to forecast the number of clean vehicles in the precise time horizons [3]. One study predicts that the economic sustainability of the buses achieves parity with their fossil fuel equivalent by 2030 when the indirect costs to human health and climate change are included [4]. One other study shows that assuming battery-electric bus adoption beginning in the year-2020, cumulative break-even occurs somewhere between 2030 and 2037 depending on the rate of battery cost decline and diesel-bus purchase prices [5].

However, at the same time, a paper emphasizes that most European countries will likely not be able to replace conventional diesel buses with replacement buses by 2050 [6]. As a result, the timing of the introduction of buses will depend on advances in technology.

The development of several charging methods is particularly important for electric buses. With the pervasiveness of electric vehicles and increased demand for fast charging, stationary high-power fast-charging is becoming more widespread, especially for the purpose of serving pure electric buses with large-capacity onboard batteries [7]. Moreover, recently, dynamic wireless power transfer (DWPT) technologies have been developed, which enable buses to charge in motion and overcome the drawback (short service range) with opportunity charging [8].

However, there are currently various barriers to the widespread adoption of electric and hydrogen buses. The technical barriers of electric buses are mostly associated with battery technology. A significant challenge is the relatively low energy density of batteries, which is directly related to a price issue on buses [3]. Therefore, the recent development in battery technology has increased the potential of electric buses to be a viable solution for public transport. Additionally, already an attempt was made to compare the possibility of the functioning of buses, trams, and trolleybuses socio-economic, environmental and technological conditions [9].

However, there are several renewable bus technologies to choose between and it can be difficult to know what alternative is preferable. So, one article developed a multicriteria assessment (MCA) method to support assessments of public bus technologies' sustainability [10].

Specially, the results obtained by $12 \mathrm{~m}$-long electric bus with the opportunity charging model outperformed the others, although it usually implies more vehicles due to the charging time spent on-route [11].

To commercialize electric buses, there are also significant considerations about the construction of infrastructure. Various studies show about detail review of infrastructure [12,13]. One paper presents an electrical infrastructure planning method for transit systems that operate with partially grid-connected vehicles incorporating onboard batteries [12]. One other paper presents an exhaustive driving cycle and passenger load sensitivity analysis for the most common city bus powertrain topologies [13].

Although the charging infrastructure and the battery capacity are in shortage to operate electric buses popularly, it has sufficient effects as a means of public transportation when used in the small downtown routes where the operation distances are short [14]. Moreover, the operation range remains a challenge for passenger electric vehicles but for electric public buses it may not be considered as a problem if the operation of buses is well managed in terms of charging and route planning [3]. Additionally, unlike diesel buses, electric buses require a dedicated charging infrastructure for their operation resulting in increasing the initial costs. This infrastructure, however, have a longer lifetime than the buses and one charging unit can be utilized by several buses. Therefore, the eventual cost impact on the life cycle cost of the bus fleet operation is not that remarkable [15].

Unlike battery buses, line configuration is not an economic driver for hydrogen bus operations. The current range of $\mathrm{H}_{2}$ buses is sufficient to cover the expected daily mileage. However, for hydrogen mobility, the supply infrastructure and the associated fuel costs are of crucial importance. Its development is associated with high investment costs and legal obligations (BImSchG, BetrSichV), which could be a hurdle for transport companies for an initial small-scale trial of the technology. In this paper, to compare the costs of the 
internal combustion diesel buses with the costs of the electric and hydrogen busses, the Total Cost of Ownership (TCO) has been evaluated. This value, expressed in $€ / \mathrm{km}$ is of fundamental importance since the economic performance will be the most crucial for the future development of these new technologies [16,17].

There are only a few research studies that show a total cost of ownership (TCO) analysis of alternative power train technologies for specific cities [1,15,18-23]. In each case study, several scenarios specialized in the cities were presented, with each presenting various research focuses. Some studies have focused on the placing of charging infrastructure of electric buses suitable for cities, and a scenario has been set with weight on the charging schedule accordingly $[1,21,22]$. Particularly, in studies targeting small to midsize cities, they have different strategies to build up several scenarios with the cost parameters. They suggest specific scenarios according to an energy storage system replacement [16], infrastructure construction cost [18], investment cost [19], and different battery types [20].

However, there is no comprehensive study presenting a future TCO scenario specialized in a small to midsize city by predicting the cost development trend of several parameters, through a comparison of past and present cost for electric and hydrogen buses. In this research, plenty of datasets based on market prices and multiple literature reviews present the differentiation from other studies.

This study presents TCO models of city bus configurations to assess public transport in a small to midsize city to be suitable for the transition to alternative power train technologies. Several TCO scenarios are examined in order to assess the influence of each factor. As a result, the economical comparison to currently dominant conventional diesel city buses can be conducted at a glance.

\section{Methodology}

The total cost of ownership (TCO) has been identified as one of the main decision factors for the viability of investment for all types of buses $[18,24]$. TCO considers all expenses linked to owning and operation of public buses and is used to calculate the cost experienced during the entire life cycle [19,24].

TCO consists of purchase costs and the running costs for maintenance, operation and fuel cost and infrastructure costs, including its CAPEX and OPEX, all with consideration of their lifetime [25]. TCO has been calculated based on operational data and values from literatures. Although various efforts have been made to calculate the TCO of electric and hydrogen buses, in the literature, there is a lot of uncertainty in the estimation of TCO. As those buses have not been manufactured yet in large-volume series, it is difficult to estimate the related costs precisely. Additionally, because their production is not mature enough when compared to conventional public buses, it is hard to estimate the technological development of alternative buses in terms of costs [15]. In particular, differences in the taxation policies of the energy in different countries make the overall cost calculation quite difficult [15], but in this study they are not considered.

The TCO analysis presented in this study increases accuracy with the expansion of the data pool obtained from detailed literature research. The flowchart of building up the TCO model is given as in Figure 1. In order to establish TCO models, first an analysis of the Offenburg bus line is required, which selects a suitable bus line to replace with electric or hydrogen buses. For e-bus additionally, it should determine the battery capacity required based on the total length of the line and the distance traveled per day.

With data from literature review, the annuity method is applied to calculate the TCO. It is used to calculate present values considering interest rate and lifetime and gain comparability of cash flows which differ in timing and amount. In this method, all payments should convert into equal annual amount. This annual rate is called an annuity, $a$ :

$$
a=I_{0} \cdot f_{\mathrm{wg}}=I_{0} \frac{i(1+i)^{n}}{(1+i)^{n}-1}
$$


During the conversion, the investment $I_{0}$ is multiplied by the annuity derivation rate, $f_{\mathrm{wg}}$. The rate $f_{\mathrm{wg}}$ is the reciprocal of the NPV factor, where $i$ is the interest rate (or discount rate) and $n$ is the whole lifetime of the product.

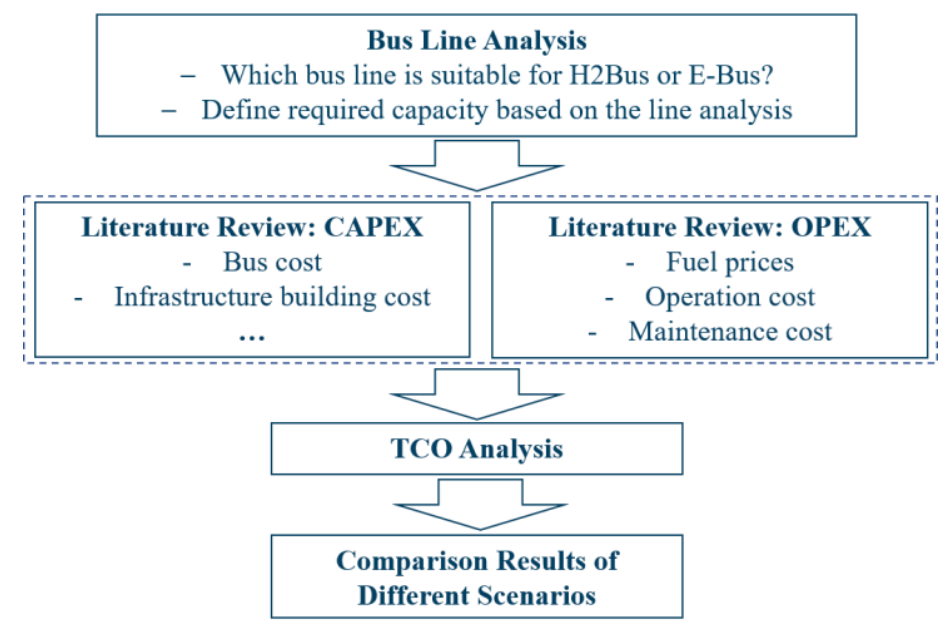

Figure 1. Flowchart of the proposed total cost of ownership model.

\section{Bus System in Small to Midsize Cities}

\subsection{Structural Analysis in a Small to Midsize City in Germany: Offenburg}

It is a well-known fact that there is a strong interdependence between settlement structure and transport system. Spatial and settlement structures influence the demand for transport to different degrees. For structural analysis, we chose a small to midsize city, because mostly this kind of city does not offer a rail-bound local public transport system so we can neglect the mode choice of users and its effects in the TCO analysis. In this respect, our methodology is a generic one that can be applied to other small to midsize cities. A common international definition of a small city is not available; therefore, we prefer to use the term small to midsize cities which covers the cities with a population of up to 100,000. Applicability of methodology to other small to midsize cities with similar settings and comparability would be therefore straightforward.

In this section, firstly, traffic demand in Offenburg is analyzed, then the structural characteristics of the bus system in the city of Offenburg and surrounding are evaluated and possible transport lines for battery-electric and hydrogen operation are determined. The results of these structural analyses are briefly presented in this section.

Offenburg is the largest city in the Ortenau district with a population of around 60,000 and as a regional center, is divided into central locations within the Southern Upper Rhine region in Germany. The spatial distribution of the population among the neighborhoods shows a typical picture of urban areas with high density in the center and relatively low density in the suburban and rural areas. About one-third of the population in the city of Offenburg is between 18 and 45 years old. Another third is between 45 and 65 years old. Twenty-two percent of the total population is older than 65 and about $16.5 \%$ is between 0 and 18 years old. In the city of Offenburg, about $67 \%$ of households (30,264 in total) are one- and two-person households, with the highest proportion of these in the city center.

An important indicator that explains the spatial-structural relationships in a quite simple way is the commuter balance. As the headquarters of a large number of nationally and internationally important small and medium-sized as well as large companies, the city of Offenburg generates transport demand primarily through incoming commuters. However, there are no current statistics on the modal split of commuters in Offenburg and their detailed spatial distribution. To examine the transport demand and to scrutinize the public transport system regarding the bus system and electrification, there is a need for a detailed traffic model. In this study, we used a Germany-wide traffic demand model VALIDATE (PTV Group) [15] which is commercially available. 
The VALIDATE traffic model is a calibrated model that provides car and truck loads for the entire German main road network. It consists of:

- $\quad$ an attributed network model of the main road network,

- $\quad$ the traffic volumes and thus the demand (typical working day demand matrices Tuesday-Thursday) for cars and trucks and

- $\quad$ the assignment of the demand to the network.

The network is derived from a digital road network (NAVTEQ) [26]. It consists of about 2 million nodes, about 120 million links and 10,193 traffic cells. The traffic behavior or traffic demand was derived from the national survey data [27]. The resulting demand matrices were calibrated with the data (based on the counted cross-sectional traffic volumes DTVw) from 70,000 counting points. Subsequently, this traffic demand is assigned to the network using the VISUM traffic modeling software (PTV Group) [28]. As a result of this assignment, information is available on route choice between source-destination relations and hourly as well as (work-) daily loads.

After the traffic assignment, there is a demand for approx. 8 million relations that are used throughout Germany. Each relation has information about the routes used, which consist of several nodes and edges. Since traffic is always destination-oriented and purposebound, conclusions can be drawn from Figure 2 about the activity patterns in Offenburg and the surrounding area. With more than 20,000 trips per day (marked in red), the city of Offenburg is of course one of the most important traffic generators in the region.

Furthermore, the commuter links (black bars) show that the majority of commuters commute between neighboring cities. The share of commuters who commute far beyond the municipal boundaries is lower in comparison.

Basic analysis of traffic demand gives us sound information about the travel patterns of private transport in the region. However, we need additional information on the public transport system in the region, to completely understand the demand structure and to define the lines to be electrified. Therefore, in the second part of the structural analysis, we evaluated the public transport system in the region.

Main data resources for the analysis are the data extracted from the central stop directory (zHV) [15] and individual timetables of the existing lines.

The structural analysis follows the following steps:

1. Processing of data from $\mathrm{zHV}$

Conversion of csv tables (information about stops regarding coordinates, operator, name ... ) into GIS format.

2. Digitization of the existing timetables

Conversion of pdf tables into table format

3. Merging of the stops and timetables in GIS

Assignment of the stops or lines to the respective timetables

Since the data about routes on the road network are not available, they are additionally generated by digitizing the stops and timetables, in which the stops are mapped as point feature in GIS and their coordinates are used to query the route between each stop via Google Directions API.

Furthermore, service frequencies of the lines are derived from the above-mentioned digitized schedules, i.e., number of trips per weekday/weekend are aggregated between stops. In this way, the trip lengths of the lines are presented differentiated by time (Veh. $\mathrm{km} /$ day/week/year). This information forms the core of the structural analyses.

After an evaluation of the detailed analysis of the characteristics of the structures presented here, the following evaluation criteria emerge for the selection of lines with hydrogen and battery electric operation:

- Accessibility

- $\quad$ Potential of modal shift

- Quality of infrastructure 


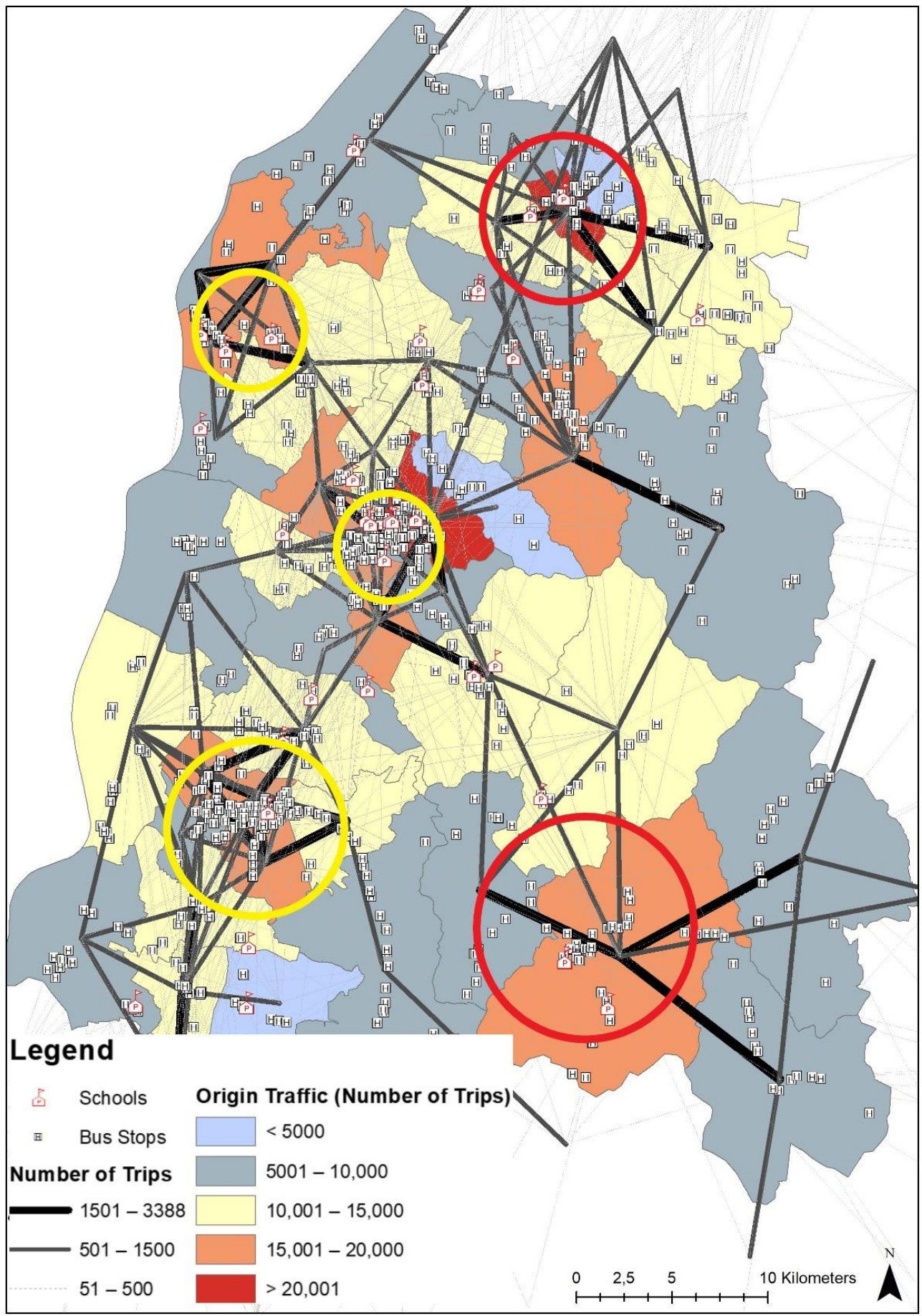

Figure 2. Connectivity and car dependency as the potential for modal shift.

Accessibility can be considered as a spatial as well as a social, economic, psychological or legal phenomenon. In this study, we define the accessibility as an indicator of the connection quality of the transport system. Here we use the proportion of the population living within a certain radius of the stops to determine accessibility. According to the simple accessibility indicator, almost all districts in Offenburg and the surrounding area are within a $500 \mathrm{~m}$ radius of a bus stop.

From the population's point of view, the attractiveness of the public transport service is mainly measured by the accessibility and connection quality of the public transport system. 
The concept of modal shift is generally based on the idea of shifting transport demand from private motorized transport to public transport and/or non-motorized transport.

Modal shift measures are usually based on a combination of push and pull factors: users are persuaded to change their mode of transport if the benefits of choosing a more environmentally friendly alternative or an alternative that makes more sense for society as a whole exceed the benefits of choosing their own car. Measures that increase the attractiveness of public transport or bicycles thus "pull" demand away from private cars. Conversely, appropriate measures (such as $30 \mathrm{~km} / \mathrm{h}$ zones and parking management) can make private transport less attractive (=push).

Approaches to modal shift reach their limits wherever individual stages of typical trip chains are particularly car dependent. Conversely, measures that make car use less attractive for individual trip chains (such as consistent parking management in the city center) can also influence the model choice of individuals in favor of public transport.

In this context, the degree of car dependency and the accessibility quality were used as decisive criteria for the shift potential. As shown as synthesis map in Figure 2, some districts in Offenburg and the surrounding area have potential for modal shift. The areas marked in red have a high dependency on private car (high traffic volume) and a relatively poor degree of public transport infrastructure in terms of connectivity. The areas marked in yellow also have a very high traffic volume, but at the same time a good degree of connectivity and accessibility. In this context, it would make sense to convert the lines operating in the areas marked in yellow to hydrogen and battery-electric propulsion.

In summary, the decisive characteristics for the selection of suitable lines are the annual mileage of the lines (thereby, among other things, reducing pollutant emissions possible), routing through the city center (quiet and clean ride) and the potential of higher passenger numbers. In particular, the city bus lines (S1 to S9) and the regional line (R106) would be recommended for operation with hydrogen and battery-electric vehicles (Figure 3, Appendix A).

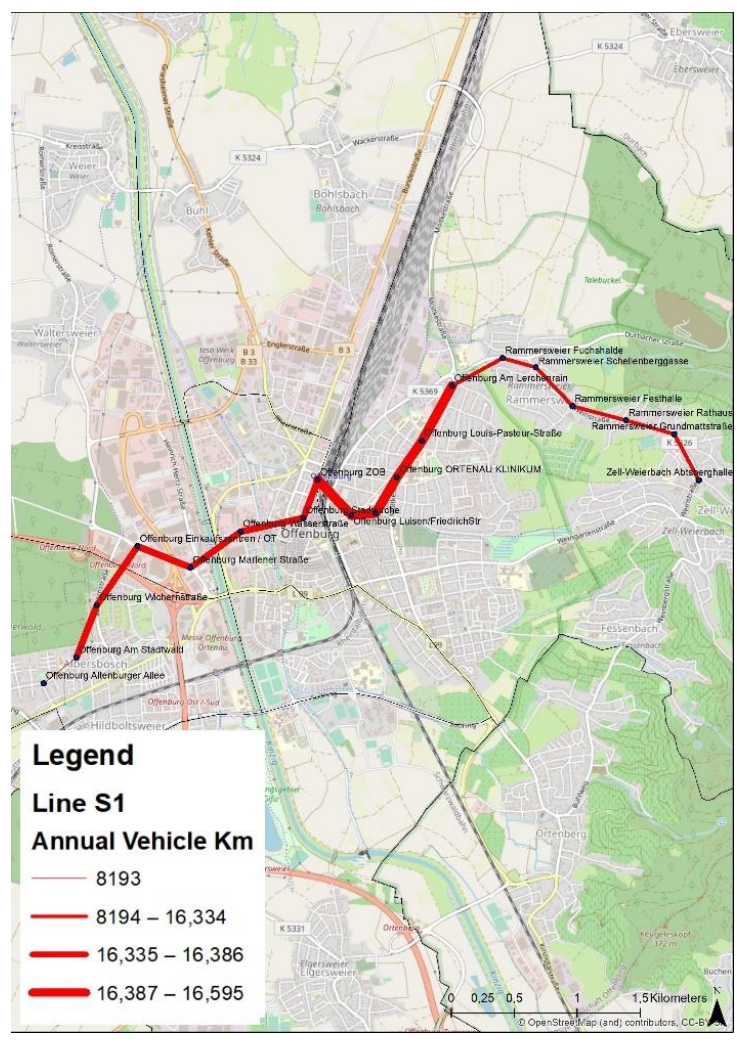

(a)

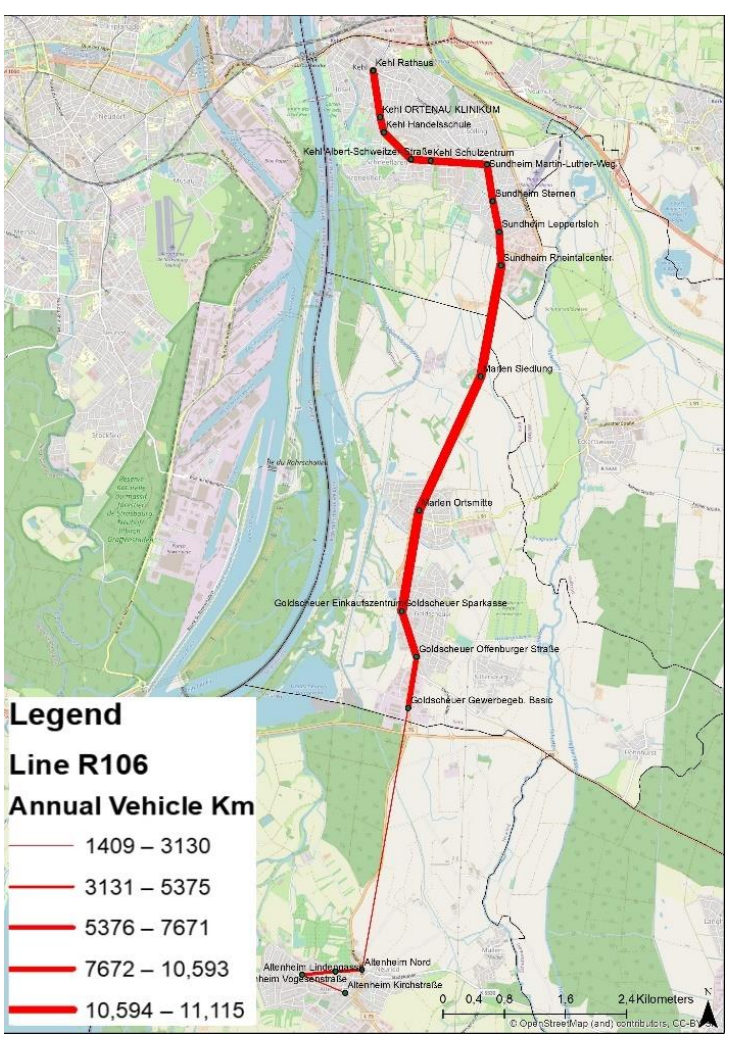

(b)

Figure 3. Structure analysis for bus lines in Offenburg: (a) city bus line S1; (b) regional line R106. 
Besides evaluating various structural characteristics for selecting suitable lines, another aspect, namely, acceptance, is a very important factor affecting the use of suggested lines with hydrogen and battery electric powered bus systems.

\subsection{Acceptance Study in a Small to Midsize City in Germany: Offenburg}

In addition to the evaluation of various structural characteristics of the city of Offenburg, insights from the population residing in the region are also an important source of information when it comes to the findings on the acceptance of hydrogen and battery electric powered bus systems. The use of such vehicles has been widely discussed in recent years. However, at present, they are still an unknown means of transport among the population. Only a few have already tested or observed such a vehicle. In this study, we have also conducted CATI and on-site surveys to investigate existing knowledge of hydrogen and battery electric buses among the population, their acceptance, and intention to use them.

Figure 4 shows the result of a questionnaire about Offenburg citizens' acceptance of the hydrogen bus from 150 participants. Overall, the evaluation outcome of $\mathrm{H}_{2}$ buses was very positive. As can be seen in Figure 4, a large proportion of respondents rated $\mathrm{H}_{2}$ buses as a sustainable, environmentally friendly, and attractive means of transport. In addition, respondents expressed that they would like to ride $\mathrm{H}_{2}$ buses and consider them an environmentally friendly means of transportation and would be proud to use them.

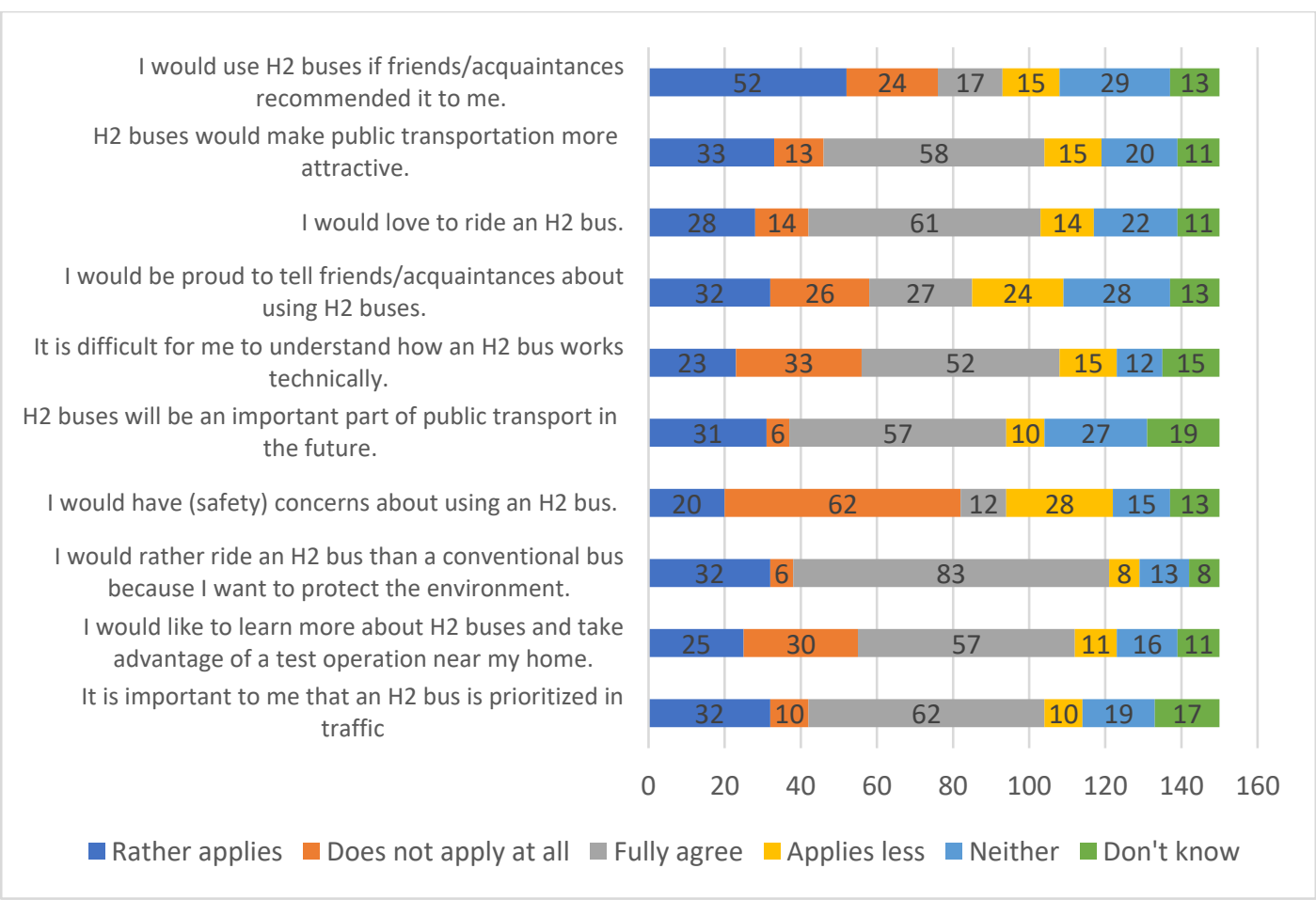

Figure 4. Result of questionnaire about Offenburg citizen's acceptance with hydrogen bus.

This suggests that there is a demand for eco-friendly buses from citizens, which motivates this study.

\section{Electric Bus Implementation}

\subsection{Vehicles Costs}

The purchase cost of the electric bus is largely divided by different charging methods. This study focused on depot charging and pantograph charging electric buses. The depot charging method is the most widely used and is also called overnight charging because it is a method of charging the bus at nighttime when is not operating. Pantograph charging 
uses roof-mounted equipment that charges completely the battery system within minutes, consistent with the concept of opportunity charging, which charges several times a day during run time [29].

Table 1 shows the costs for the individual vehicle components of these two charging systems. The base vehicle body has no cost differences due to a high degree of technical consistency. For a diesel vehicle, the drive system cost must also include an automatic transmission and exhaust gas after-treatment systems, whereas these are not required for an electric bus. However, in addition to the electric motor, significantly more complex power electronics are required, which account for a significant part of the costs for electric buses [30].

Table 1. Purchase costs of electric battery buses for two different charging methods.

\begin{tabular}{cccc}
\hline Category & $\begin{array}{c}\text { Overnight Charging } \\
\text { E-Bus }\end{array}$ & $\begin{array}{c}\text { Pantograph } \\
\text { Charging E-Bus }\end{array}$ & Unit \\
\hline Vehicle body & 210 & 210 & $\mathrm{k} €$ \\
Drive system and power & 105 & 105 & $\mathrm{k} €$ \\
electronics & 5 & 15 & $\mathrm{k} €$ \\
Bus side charging components & 320 & 330 & $\mathrm{k} €$ \\
Total costs & &
\end{tabular}

Figure 5 shows the investigated costs of $12 \mathrm{~m}$ e-bus, varying from 235,000-420,000 $€$ without batteries. Most research papers refer that purchase costs of electric buses are 2.5-3 times higher than diesel buses [22,31], but they consider battery costs. The average price is around $300,000 €$, with little change in price compared to the average price five years ago and today $[1,18-22,31-33]$.

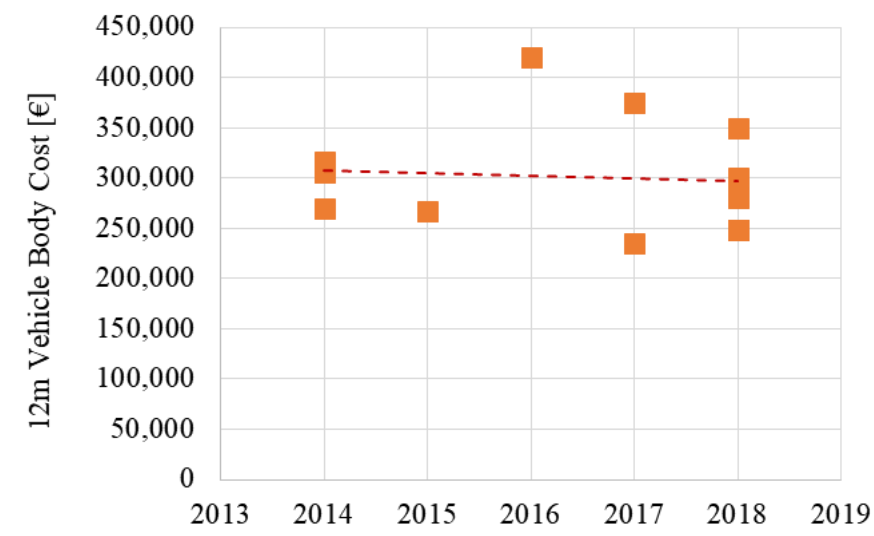

Figure 5. Purchase costs of $12 \mathrm{~m}$ electric buses excluding the batteries.

Since this report separately calculates the impact of each factor on the bus on the price, we attempt to separate the price of the battery and the vehicle body. Nevertheless, since many studies report the price of an e-bus including batteries, it was used to determine the suitability of the expected body price.

Figure 6 shows the investigated costs of e-bus, varying from 430,000-750,000 $€$ with batteries [20,29,34-37]. Unlike Figure 4, the change in bus price from 2009 to 2018 is remarkable, and this is expected to be due to the change in battery price. The vehicle cost including the battery in 2020, was calculated based on a $260 \mathrm{kWh}$ electric bus with a body price of $300,000 €$ and a battery price of $667 € / \mathrm{kWh}$. Looking at the trend of e-bus price fluctuations, it can be seen that the expected value is reached in 2020. In other words, the price of the bus body, which is already expected to be around 300,000 euros (Figure 4), is expected to be a possible price in light of the trend of falling battery prices, which will be studied in more detail by looking at the change in battery price in the next section. 


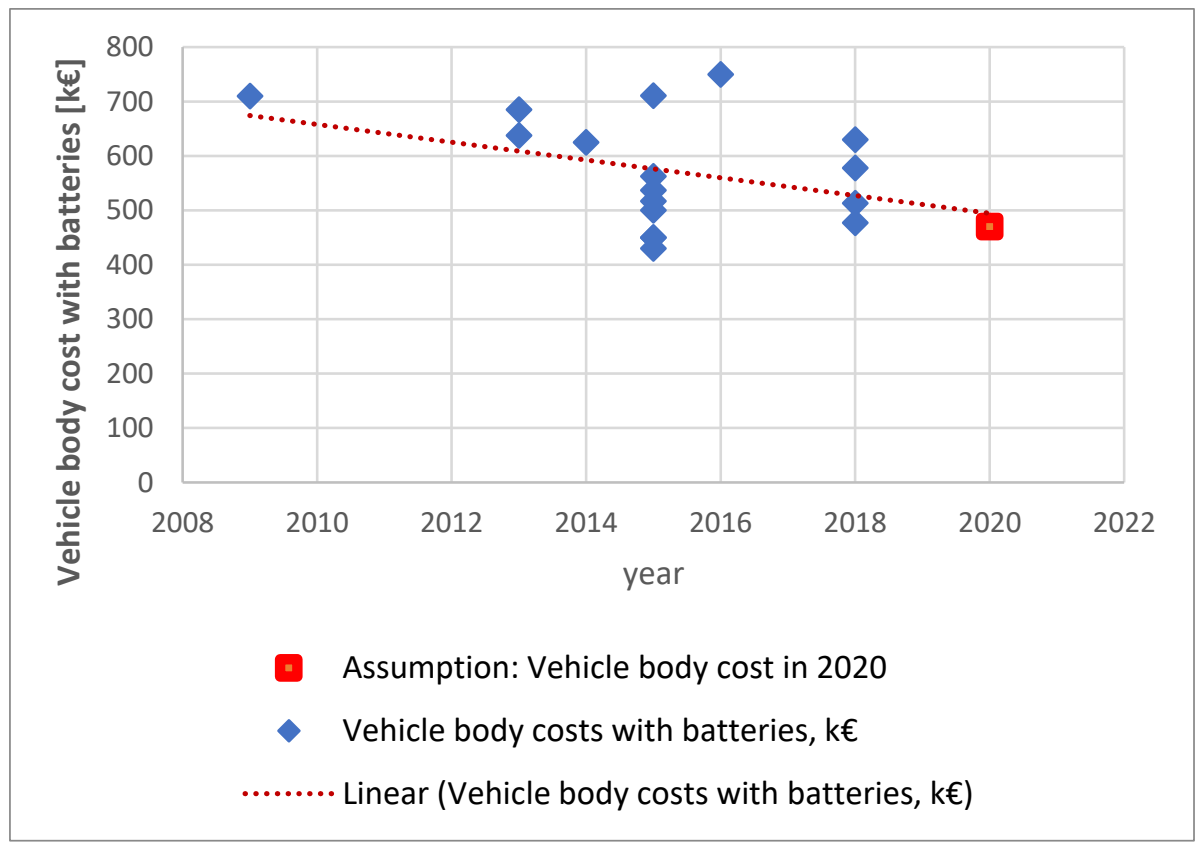

Figure 6. Vehicle body cost including the batteries in the past decade from 2009 to 2018 vs. expected price in 2020 [20,34-38].

\subsection{Battery Prices}

The battery of an electric bus is a major price driving element in the TCO model. Additionally, electric energy storage systems have a limited life of around six-seven years, which is usually half of the life of electric buses. However, unlike the costs of electric buses, battery price showed a high reduction in the last 10 years. With the increasing demand for lithium-ion batteries from electric vehicles, the battery manufacturing industry is growing up dramatically, which puts pressure on battery prices [29].

However, the battery technology still has not been mature enough in terms of durability, costs and energy density for a breakthrough of large-scale commercialization of electric city buses. Therefore, the improvement of battery costs is expected since the technology is still developing [15].

Figure 7 presents an overview of different estimates reported in 2008-2018 to trace the costs of Li-ion battery packs from battery electric vehicle manufacturers. The data points reveal that costs are coming down, but with large uncertainties on past, current and future costs of the dominating Li-ion technology. Learning rates based on an experience curve following from cumulative installed Li-ion battery storage capacity have been estimated to between $15 \%$ and $16 \%$ in the reviewed literature. The rate of decline for market leaders is much lower than for the whole industry and has declined by $10 \%$ annually [38].

The issue here is that the price of the battery is often mixed with the batteries on the personal electric vehicles and the buses. E-buses have different battery pack prices compared with personal EVs. However, because the technology development of battery affects both EVs and e-buses, the outlook presented in the study still can be considered to measure the downward trend.

Bloomberg New Energy Finance (BNEF) 2018 study shows reliable battery price data that are consistently mentioned in several papers and include forecasts till 2030 [29]. The price for battery packs overall has fallen by $24 \%$ since 2016 and $79 \%$ since 2010 . The historic learning rate for EV lithium-ion battery prices from 2010-2018 was around $18 \%$. Based on this, expected battery prices continue to decline, reaching $86.4 € / \mathrm{kWh}(\$ 96 / \mathrm{kWh})$ in 2025 and $63 € / \mathrm{kWh}(\$ 70 / \mathrm{kWh})$ in 2030 [29]. 


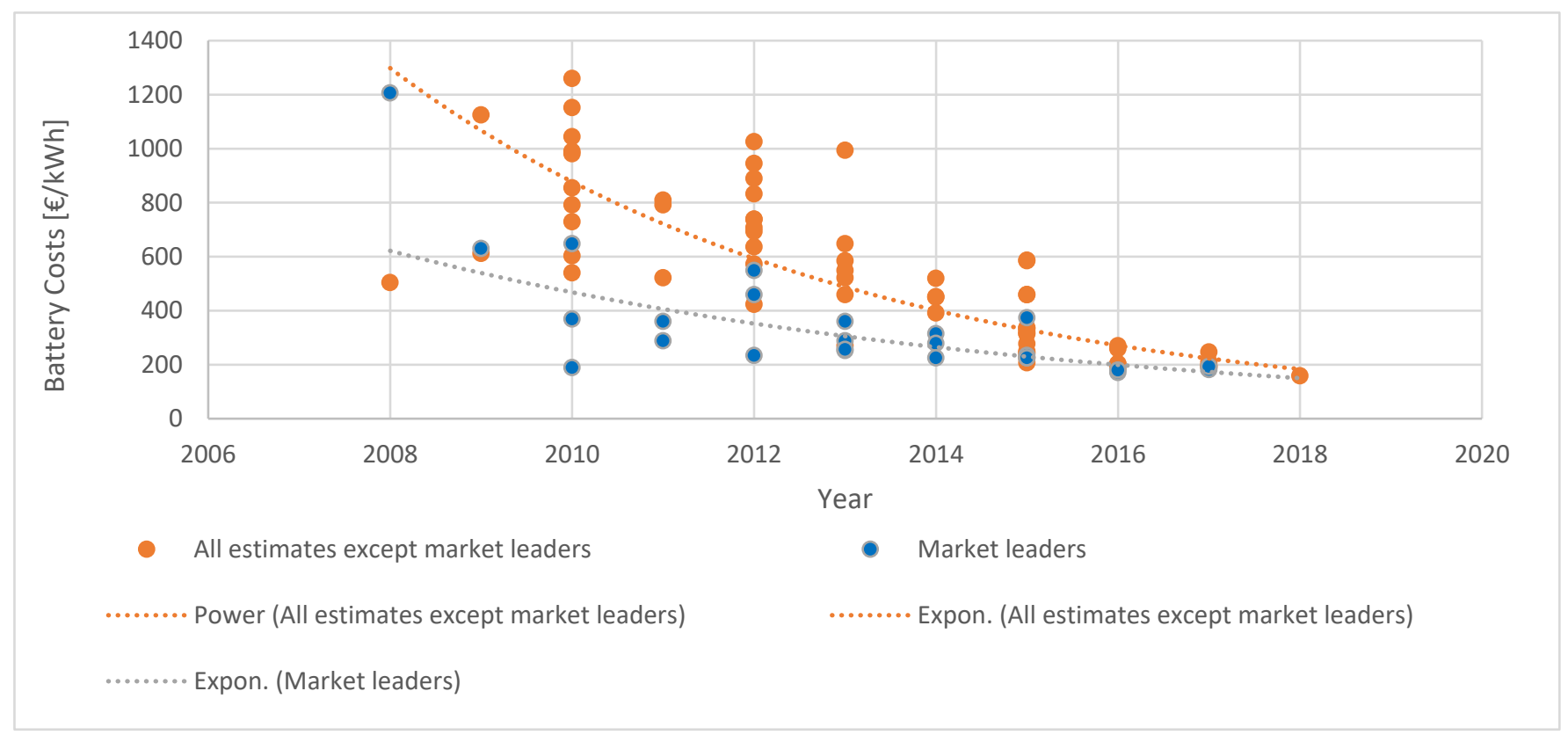

Figure 7. Li-ion battery pack costs based on data from literature reviews.

However, there is a huge gap between battery pack costs in the academic literature and actual supply prices in the real e-bus battery market. As storage technology advances, rapid declines in prices are emphasized in all studies, but the actual market price of batteries applied in bus purchases is far from the expected drop in the research.

In 2018, actual market prices for high-capacity batteries range from $600-700 € / \mathrm{kWh}$. Low-capacity batteries, commonly used for pantograph charging, are priced from $1000-1200 € / \mathrm{kWh}[18,21,30,39,40]$. This value was confirmed even at meetings with various e-bus manufacturers, and it is determined to be the actual price. Although the results of many studies of the literature review are two-three times higher from the actual prices, they are meaningful because they allow us to look ahead to a price trend.

\subsection{Energy Consumption}

The choice of the size of the battery in an e-bus depends heavily on how many kilometers per day it will be required to run. Therefore, in the largest cities, where the daily distance travelled by a bus can often exceed $300 \mathrm{~km} /$ day, operators are more likely to deploy e-buses with larger batteries, but small to midsize cities with average driving distances of around $160 \mathrm{~km} /$ day, are better served by cheaper e-buses with smaller batteries [29].

In addition, these small batteries provide the vehicle with high energy consumption. Figure 6 shows the vehicle efficiency of the e-bus from 2015 to 2018.

In Figure 8, the fuel efficiencies presented in several reports range from $0.675 \mathrm{kWh} / \mathrm{km}$ up to $2.1 \mathrm{kWh} / \mathrm{km}[2,29,31,41-45]$. In particular, the efficiency of the $374 \mathrm{kWh}$ battery model proposed by Chinese electric bus company Brand Yutong in 2018 [44] is $1 \mathrm{kWh} / \mathrm{km}$, reflecting the latest technological growth. That is, as of 2018, the average efficiency value is $1.3 \mathrm{kWh} / \mathrm{km}$, but due to the predicted growth, the energy consumption value in this report is defined as $1.1 \mathrm{kWh} / \mathrm{km}$. 


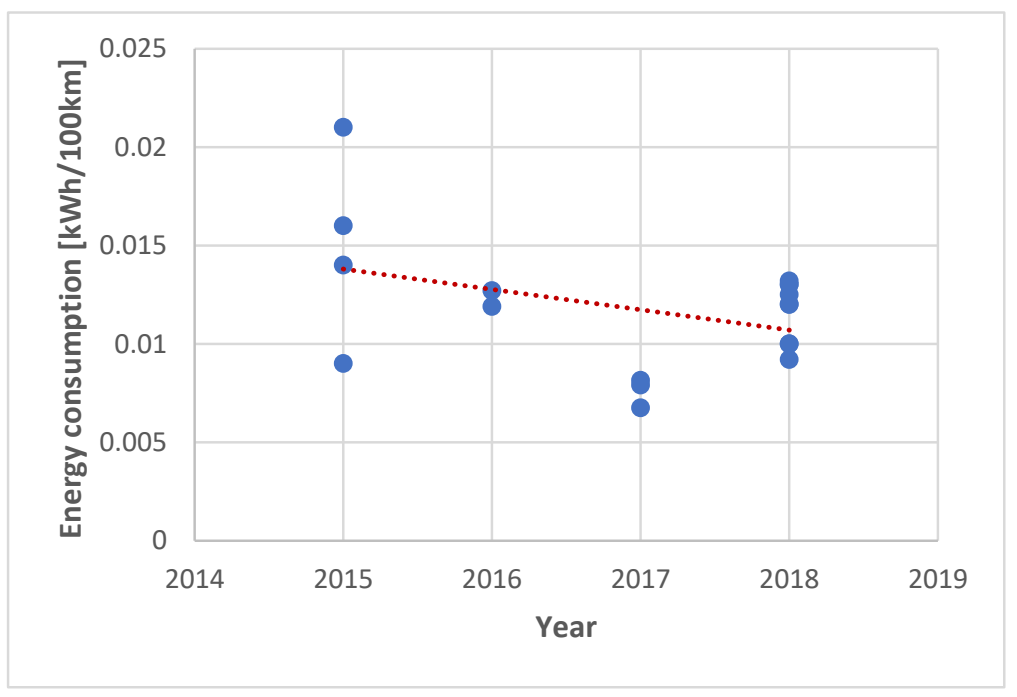

Figure 8. Energy consumption of electric buses from 2015 to 2018.

\subsection{Electricity Price in Germany}

The flow of electricity prices has a significant impact on the TCO results. Figure 9 shows BDEW's electricity price analysis for 2019 and future outlook according to EEG surcharge. Electricity prices up to 2019 represent prices charged to companies with an annual consumption of $160 \mathrm{MWh}$ to $20 \mathrm{GWh}$ [46]. Electricity prices have been rising until 2019 , but the main reason in recent years is the EEG surcharge. Particularly in the period from 2012 to 2015, the EEG surcharge was strongly influenced by shifting effects between the years $[41,46]$.

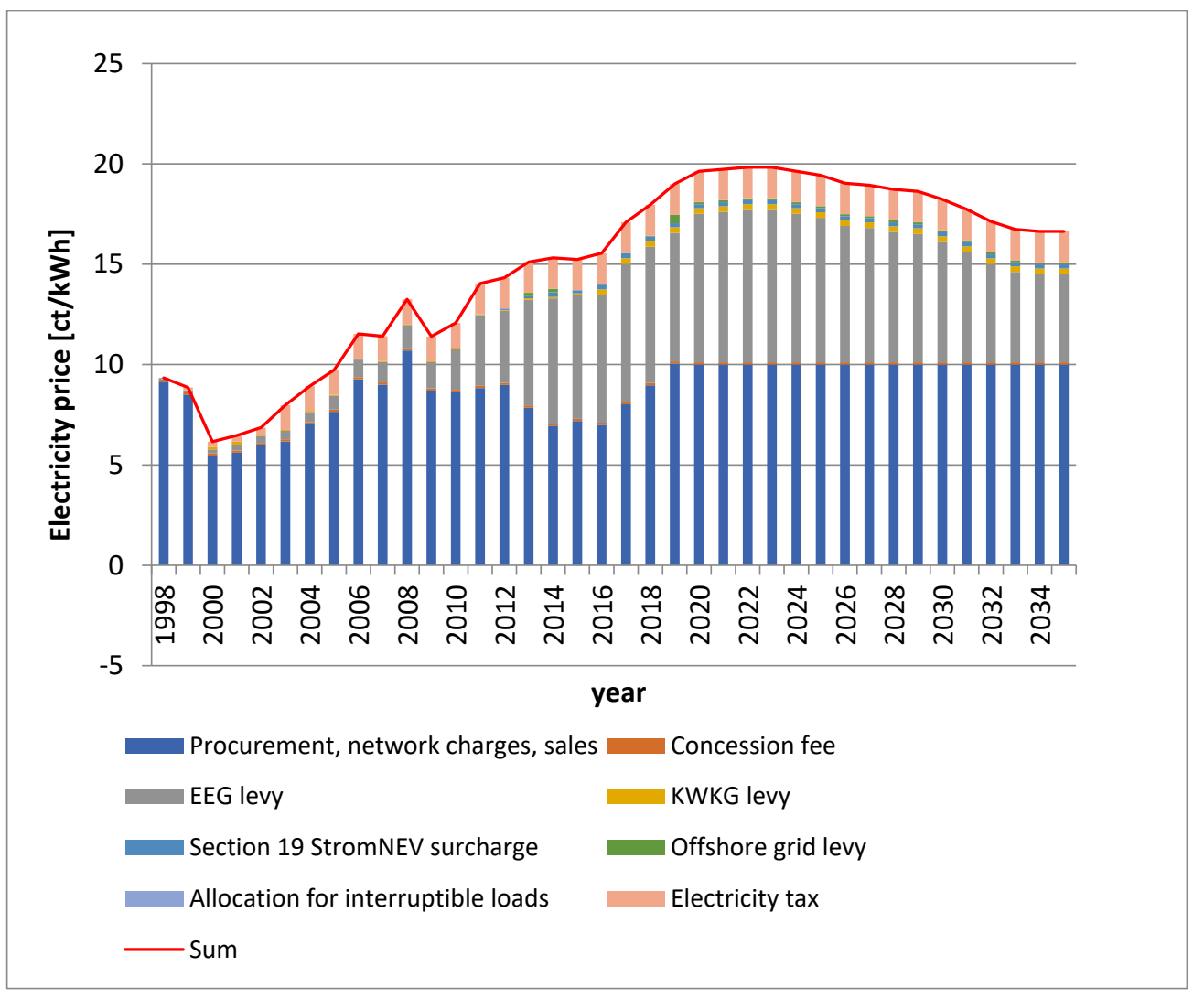

Figure 9. BDEW electricity price analysis 1998-2019 and EEG surcharge changes up to 2035, and $1 \mathrm{ct}$ (cent) defined as $0.01 €$. 
Given the expectation of a high EEG account surplus, it can be assumed that for the future the surcharge will remain essentially stable. In this study, it is assumed that the electricity trading price remains constant after 2019. As a result, the total price of electricity also declines as the EEG-surcharge decreases, reaching $16.63 \mathrm{ct} / \mathrm{kWh}(0.1663 € / \mathrm{kWh})$ in 2035.

\subsection{Electric Bus Operation Conditions for Two Scenarios}

In response to citizens' demand for emission-free buses and the trend of other cities that are moving to e-bus, the Offenburg city is considering introducing a new type of bus to reduce greenhouse gas emissions.

In this city, sixteen $12 \mathrm{~m}$-buses and two articulated buses operate in bus line S1 to S9 on weekdays. With bus line analysis, we present an approach to analyzing the costs and benefits of electric bus fleet operation concerning different charging scenarios.

- In the first scenario, only one depot charging station is placed for 2 electric buses.

- In the second scenario, 5 depot or 1 pantograph charging stations are considered for 11 electric buses.

The analysis is focused on minimizing the total cost of ownership (TCO) depending on the cost parameters. The bus size, route duration and energy consumption are constant to make fair comparisons. Even though we only consider a case example, and the results are not universal, it gives an overview of cost analysis for public electric buses in a small to midsize city.

\subsubsection{Depot Charging: 2 Buses Scenario}

Offenburg city bus lines S5 and S7 are the shortest of all the bus lines and have rarely high hills. In respect to the structural analysis, these two city bus lines are chosen as focus in the " 2 buses scenario" for battery electric buses.

In Table 2, the daily route is $169 \mathrm{~km}$ long per vehicle, and therefore required capacity is $185.9 \mathrm{kWh}$ considering energy consumption of $1.1 \mathrm{kWh} / \mathrm{km}$. Since depot charging maximizes bus usage by charging once a day at night, extra capacity is required for safety reasons. Moreover, by way of precaution, for waiting time for passengers to get off and on, or for an unexpected stop or accident, an additional capacity of the battery is required to be calculated. Therefore, by adding up around 30\% of the total, $260 \mathrm{kWh}$ was determined as the capacity of mounted batteries for the route S5 and S7.

Table 2. Line information of line S5 and S7 for 2 buses scenario.

\begin{tabular}{cccc}
\hline Category & Mon.-Fri. & Sat. & Unit \\
\hline Daily distance & 169 & 125 & $\mathrm{~km} /$ day/vehicle \\
Required capacity, energy consumption: $1.1 \mathrm{kWh} / \mathrm{km}$ & 185.9 & 137.5 & $\mathrm{kWh} /$ day/vehicle \\
Required battery capacity & 260 & 200 & $\mathrm{kWh} /$ day/vehicle \\
Number of days per year & 261 & 52 & day \\
Required number of bus & 2 & 1 & vehicle \\
\hline
\end{tabular}

\subsubsection{Pantograph Charging: 11 Buses Scenario}

Pantograph charging allows fast charging with high power from 300 to $450 \mathrm{~kW}$, with short waiting times at the bus stops. Because one charging station can handle around 10 buses or more with controlled operation schedules, switching to the electric bus as much as the charging station can afford, minimizes costs.

All city buses pass through the Offenburg central station. The time and distance to reach the destination and return to the station are different for each line (Table 3). S5 and S7 have the shortest route, and S6 and S8 have two to four times longer routes than other lines. Based on that, for line S6 and S8, the battery capacity requirement is higher, and the charging time is also longer than others. 
All buses stop just for around 2 min at the bus stop in front of train station. In addition, because about 10 buses have to share one charging station, buses that take a long time to charge are not suitable for pantograph charging.

Table 3. Line information of line S5 and S7 for 2 buses scenario.

\begin{tabular}{cccccc}
\hline Line & $\begin{array}{c}\text { Required } \\
\text { No. of Bus }\end{array}$ & $\begin{array}{c}\text { Route } \\
{[\mathbf{k m}]}\end{array}$ & $\begin{array}{c}\text { Duration } \\
{[\mathbf{m i n}]}\end{array}$ & $\begin{array}{c}\text { Required Capacity } \\
{[\mathbf{k W h}]}\end{array}$ & $\begin{array}{c}\text { Charging Time } \\
{[\mathbf{m i n}]}\end{array}$ \\
\hline S1 & 2 & 7.5 & 29 & 8.25 & 1 \\
S2 & 2 & 7.7 & 26 & 8.47 & 1 \\
S3 & 2 & 8.9 & 27 & 9.79 & 1 \\
S4 & 2 & 7.3 & 32 & 8.03 & 1 \\
S5 & 1 & 2.6 & 12 & 2.86 & 6.5 \\
S6 & 2 & 34 & 50 & 37.4 & 3.74 \\
S7 & 1 & 3.4 & 14 & 18.26 & 0.5 \\
S8 & 2 & 16.6 & 52 & 11.11 & 2 \\
S9 & 1 & 10.2 & 40 & & 1.5 \\
\hline
\end{tabular}

The battery pack of the bus produced by each manufacturer has a certain capacity, and in the case of the pantograph model, it is approximately $90 \mathrm{kWh}$. Additionally, if it has an insufficient capacity, the C-rate will be too high during fast charging. This puts a strain on the battery and causes a rapid shortening of its lifespan. Technical issues are not covered in detail in this study, so further discussions are required. Of course, there are lines that can be arranged with a smaller capacity, but in the case of Offenburg City, since the bus is not only responsible for one line but also is shared, it is not possible to choose a battery pack with a different capacity for each line. Therefore, collectively, a $90 \mathrm{kWh}$ battery pack was employed in this study.

Therefore, with the exception of the two routes, the remaining lines can be recharged between a minimum of $30 \mathrm{~s}$ and a maximum of 2 min once every hour under a battery capacity of $90 \mathrm{kWh}$ and a charging power of $300 \mathrm{~kW}$. That is, with proper rescheduling, a single charging station can handle all 11 buses running on routes S1-S5, S7, and S9.

\subsection{Economic Parameters for E-Bus Scenarios}

The values of the variables required for each scenario were determined based on literature reviews. Parameters related to the depot/pantograph charging bus and parameters of the diesel bus to be compared with the results of the electric bus TCO were set.

\subsubsection{Depot Charging Scenario}

Table 4 presents the CAPEX parameters for the bus procurement for overnight charging bus type, as well as the respective battery costs in 2020/2030 and the cost of the depot-charging station, including the grid connection and construction expenses, as well as an additional cost for a power transformer. Moreover, as OPEX parameters, the electricity cost and maintenance and operational costs for bus and charger respectively are included.

Table 4. Economical parameters for the depot charging scenario.

\begin{tabular}{|c|c|c|}
\hline Parameter & Value & Unit \\
\hline Vehicle cost in 2020 & 300,000 & $€$ \\
\hline Vehicle cost in 2030 & 250,000 & $€$ \\
\hline Battery cost in 2020 & 667 & $€ / \mathrm{kWh}$ \\
\hline Battery cost in 2030 & 100 & $€ / \mathrm{kWh}$ \\
\hline Depot charging station cost in 2020 & 28,500 & $€$ \\
\hline Depot charging station cost in 2030 & 18,500 & $€$ \\
\hline Grid connection \& Planning \& Transformer cost & 15,500 & $€$ \\
\hline Electricity cost in 2020 & 0.181 & $€ / \mathrm{kWh}$ \\
\hline Electricity cost in 2030 & 0.167 & $€ / \mathrm{kWh}$ \\
\hline Maintenance \& Operation cost (Bus) & 0.11 & $€ / \mathrm{km}$ \\
\hline Maintenance \& Operation cost (Charger) & 0.14 & $€ / \mathrm{kWh}$ \\
\hline Interest rate & 5 & $\%$ \\
\hline
\end{tabular}


The annual interest rate (or discount rate) for the scenario is determined as $5 \%$ by currents research (Table 5). Therefore, in the analysis, all of the yearly costs were discounted with discount rate, 5\% using Equation (1).

Table 5. Literature review of discount rates for the TCO analysis.

\begin{tabular}{ccc}
\hline Discount Rate, $\%$ & Year & Source \\
\hline 7 & 2007 & {$[45]$} \\
3 & 2015 & {$[46]$} \\
3 & 2016 & {$[47]$} \\
7 & 2016 & {$[47]$} \\
5 & 2017 & {$[48]$} \\
2.5 & 2018 & {$[43]$} \\
4 & 2018 & {$[21]$} \\
5 & 2018 & {$[49]$} \\
\hline
\end{tabular}

\subsubsection{Pantograph Charging Scenario}

The categories of main parameters that affect the price of the pantograph charging scenario are the same as the depot charging one. Compared to the overnight e-bus charging method, the price of the opportunity charging bus is slightly increased by the charging component [25].

In the pantograph charging, the prices of batteries are located in approximately twice that of depot charging as Table 4 presents. Since the expected high-capacity battery price in 2030 is $150 € / \mathrm{kWh}$, we assume that the low-capacity battery using for the pantograph charging bus is $200 € / \mathrm{kWh}$ based on empirical data (Table 6).

Table 6. Economical parameters for the pantograph charging scenario.

\begin{tabular}{ccc}
\hline Parameter & Value & Unit \\
\hline Vehicle cost in 2020 & 330,000 & $€$ \\
Vehicle cost in 2030 & 280,000 & $€$ \\
Battery cost in 2020 & 1200 & $€ / \mathrm{kWh}$ \\
Battery cost in 2030 & 200 & $€ / \mathrm{kWh}$ \\
Pantograph charging station cost & 457,000 & $€$ \\
Coupling system and transformer cost & 58,500 & $€$ \\
Maintenance and operation cost (charger) & 5000 & $€ /$ year \\
\hline
\end{tabular}

The lifetime of the bus varies from 10 to 20 years, but considering the total research, 12 years is a reasonable value for the e-bus lifetime. The battery service life is assumed to be 6.5 years in 2020 and 7 years in 2030 for both charging strategies and subsequent battery replacement. To calculate total annual infrastructure costs, the interest rate is set at 5\%. The CAPEX parameters are derived annually based on Equation (1).

\section{Hydrogen Bus Implementation}

\subsection{Bus Fleet Sizing}

While the overall range driven per day by each bus does not appear to be a crucial parameter for assessing an opportunity charging based scenario with charging occurring directly at bus stops, this becomes a crucial point for the hydrogen option. A refueling event during the business hours would lead to unavailability of the bus which duration cannot be neglected and would impact the bus services. This impact is more important the more the refueling station is located outside the inner city, at the bus depot for instance. To properly address this question, an Anylogic (c) based model was developed to simulate the bus services based on public timetables and geographical data, taking the range of hydrogen buses into account as limiting factor, as well as the impact on the bus services of 
a refueling event during operations if needed. The Figure 10 depicts the overall structure of the model developed.

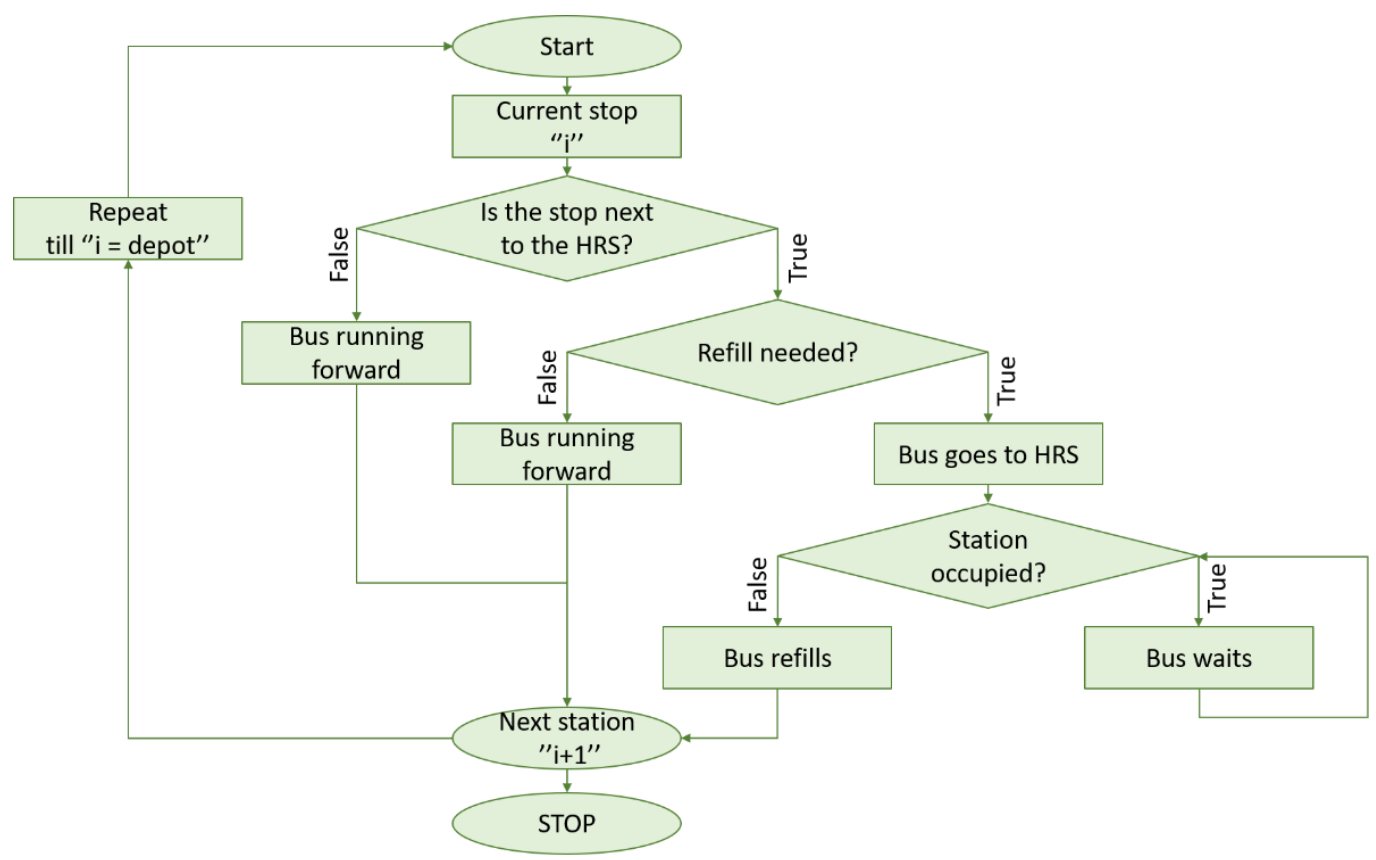

Figure 10. Overview of the logic implemented in the model.

We ran this model on each of the city lines (operating in the inner city only) and it showed that the diesel buses could be replaced 1:1 by hydrogen buses (with typical range of 350-400 km), which would refuel before or after their daily service, at a refueling station likely to be located in or close to the bus depot. Beside this, the overall mileage driven by each bus yearly was also part of the results delivered by this model and summarized in the Table 7.

Table 7. Summary of results generated by the model.

\begin{tabular}{cccccccc}
\hline Line & S1/S2 & S3 & S4 & S5/S7 & S6 & S8 & S9 \\
\hline Annual mileage & 256,500 & 161,000 & 148,000 & 95,000 & 205,500 & 184,000 & 43,500 \\
$\quad$ [km p.a.] & 4 & 2 & 2 & 2 & 3 & 2 & 1 \\
Number of buses required & 246 & 308 & 283 & 181 & 262 & 327 & 166 \\
Max Daily mileage per bus [km] & 20.5 & 12.9 & 11.9 & 7.6 & 16.5 & 14.7 & 3.5 \\
Annual H consumption & & & & & & \\
{$[\mathrm{T} / \mathrm{y}]$} & & &
\end{tabular}

\subsection{Vehicles Costs}

The purchase of $\mathrm{H}_{2}$ buses is today still mostly linked to public funded projects. In the TCO evaluation we propose in this paper, the data are based on current meta-studies conducted throughout Europe. The data are based on the publications of the FCH JU (fuel cell and hydrogen joint undertaking) and is related to demonstration projects such as CUTE, HyFLEET, CHIC, JIVE1\&2 [50], but also to manufacturer interviews. Since 2009 , the cost of purchasing an $\mathrm{H}_{2}$ bus has decreased by more than $60 \%$ [50] and was already below the FCHJU 2020 targets in 2018. Vehicle manufacturers foresee these costs approaching the $400 \mathrm{k} €$ thresholds in the near future [50] while prices are expected to remain relatively stable over the next decade according to a prospective study a Roland Berger [51]. Nevertheless, the joint procurement strategy [52] pushed by the fuel cell hydrogen joint undertaking (FCHJU) at a European level is expected to lower production costs for hydrogen buses through increased production batch and optimized production 
chains. This approach is already developed at national level, as for instance in France [53] and might contribute to effectively decrease acquisition costs for transport companies. The FCHJU study NewBusFuel, which aggregated and analyzed 2017 results of recent reference projects dealing with the implementation of hydrogen buses in the public transportation sector across Europe, suggests $430 \mathrm{k} €$ as a benchmark from 2023 [54]. This value is taken as the reference value for the reference scenario developed in this paper while a prospective scenario with acquisition cost of $360 \mathrm{k} €$ each bus also considered for the 2030 horizon.

\subsubsection{Specific Consumption}

For the specific consumption of hydrogen buses, Ballard, one of the main providers for fuel cells for buses reports an average consumption of "less than $9 \mathrm{~kg} / 100 \mathrm{~km}$ " [55], also taking the consumption of auxiliary (air conditioning, heating etc.) into account. The CHIC project monitoring the operation of 54 fuel cell buses in Europe and Canada between 2010 and 2016 showed an average consumption of $9 \mathrm{~kg} \mathrm{H}_{2} / 100 \mathrm{~km}$ for $12 \mathrm{~m}$ buses considered in our study. This average showed however, significant variations depending on road profiles, local climate, and general traffic conditions. While this value appears realistic for current vehicles for the use case of Offenburg, targets set by manufacturer for the coming years see a specific consumption below $8 \mathrm{~kg} / 100 \mathrm{~km}$. The FCH-JU also assumes a gradual reduction of the hydrogen consumption to $7.6 \mathrm{~kg} \mathrm{H}_{2} / 100 \mathrm{~km}$ in 2023 . A reference consumption of $8 \mathrm{~kg} / 100 \mathrm{~km}$ was finally selected for the present calculation, in a slightly conservative approach.

\subsubsection{Maintenance Costs}

The bus lifetime is set at 12 years of operation [54]. During this time span, the power train consisting of the fuel cell, the buffer battery and some peripheral equipment is assumed to be replaced after 6 years of operation. The assumed maintenance interval and costs for this operation are summarized in the Table 8 and are sourced from the NewBusFuel study [54].

Table 8. Parameters set for TCO calculation—hydrogen implementation.

\begin{tabular}{cc}
\hline Parameter & Hypothesis \\
\hline Bus-acquisition costs & Current: $430 \mathrm{k} €$ \\
Lifetime bus & Prospective 2030: $360 \mathrm{k} €$ \\
Lifetime power train & 12 years \\
Replacement power train & 6 years \\
Yearly bus maintenance costs (regular maintenance)) & Current: $50 \mathrm{k} €$ \\
Hydrogen specific consumption & Prospective: $40 \mathrm{k} €$ \\
\hline
\end{tabular}

\subsection{Fuel Costs: Hydrogen Onsite Production through Electrolysis}

Different options exist for the sourcing of hydrogen required to operate the buses. Hydrogen can be produced mainly from steam methane reforming (so-called gray or blue hydrogen depending on carbon capture or not), or from water electrolysis. This later case is generally preferred to decentralized applications aiming to produce hydrogen without $\mathrm{CO}_{2}$-emissions. The subsequent condition is feeding the electrolyzer with renewable electricity. In this paper, we assume the renewable electricity to be purchased at typical market price with negligible premium. Two scenarios have been investigated in order to evaluate the fuel costs based on onsite production and distribution through electrolysis. The first relies on a techno-economic dataset reflecting the current technology and power costs (reference year 2020), while the second bases on projections for 2030.

The component of the production and distribution installations were sized to be able to supply the entire fleet of 16 buses while operating at $80 \%$ load. This leads to an installed capacity of $800 \mathrm{~kW}$ electrolysis and a storage size of $500 \mathrm{~kg}$ to cover the supply of the whole 
bus fleet for one day (in order to achieve high reliability of the bus service even in the case of a component failure). The general techno-economic assumptions are summarized in the Table 9. For the year 2020, the electricity costs are assumed to be $0.18 € / \mathrm{kWh}$ (see electricity price data previously presented in the battery section). A second scenario was evaluated for the year 2030, taking a reduction of the technology investment costs into account (i.e., electrolyzer and storage reduced by $30 \%$ ), as well as a reduction of the electricity cost (dropped to $0.1 € / \mathrm{kWh}$ ). The significant electricity cost reduction assumed here mainly reflects the change in the German regulation which occurred at the beginning of 2021, allowing to exempt electrolysis installations from paying renewable energy taxes (EEG) in certain conditions.

Table 9. Parameters set for hydrogen costs calculation.

\begin{tabular}{ccc}
\hline $\mathbf{H}_{\mathbf{2}}$ Refueling Station & Value & Unit \\
\hline Electrolyzer nominal power & 800 & $\mathrm{~kW}$ \\
Specific energy consumption & 55 & $\mathrm{kWh} / \mathrm{kg}$ \\
Nominal production rate & 14 & $\mathrm{~kg} / \mathrm{h}$ \\
Investment costs-electrolyzer & 720,000 & $€$ \\
Maintenance costs-electrolyzer & $3 \%$ & $\%$ of investment costs \\
lifetime) & $30 \%$ & $\%$ of investment costs \\
Storage nominal pressure & 440 & $\mathrm{bar}$ \\
Storage nominal capacity & 500 & $\mathrm{~kg}$ \\
Investment costs-storage & 500,000 & $€$ \\
Maintenance costs-storage & $3 \%$ & $\%$ of investment costs \\
Buffer storage nominal pressure & 20 & $\mathrm{bar}$ \\
Buffer storage nominal capacity & 5 & $\mathrm{~kg}$ \\
Investment costs-buffer storage & 7500 & $€$ \\
Maintenance costs-buffer storage & $3 \%$ & $\%$ of investment costs \\
Compressor nominal power & 50 & $\mathrm{~kW}$ \\
Investment costs-compressor & 136,500 & $€$ \\
Maintenance costs-compressor & $5 \%$ & $\%$ of investment costs \\
Number of compressors & 2 & - \\
\hline
\end{tabular}

Based on this assumptions, the resulting hydrogen production costs were evaluated to $13.1 € / \mathrm{kg}$ in 2020 and $7.6 € / \mathrm{kg}$ in 2030 , assuming a discount rate of $5 \%$. While these values appear relatively high to make the hydrogen-based solution cost competitive, this approach nevertheless enables to decarbonize this transport application while having no impact on current operations organization. This fuel costs have been then used to perform a total cost of ownership calculation at the level of the whole city bus fleet. Additionally, a sensitivity analysis was later performed for the 2030 scenario to further investigate the impact of fuel cost on the TCO for the hydrogen solution (fuel costs varying from 7.6 to $5 € / \mathrm{kg}$ ). Hydrogen infrastructure costs are indeed strongly impacted by sizing effects, which lead to reduced costs. Assuming a broad development of hydrogen applications in the region for the next decade, the resulting generation and distribution costs would be significantly lowered by making benefit of scaling effects.

\section{Diesel Bus Implementation}

Cost-effective parameters of the diesel bus are also collected to compare the TCO with the electric bus (Table 10). As one of OPEX parameters, the average price of a diesel bus is set to $250,000 €$. An important parameter in CAPEX on diesel buses is the diesel price. The diesel market price in Germany for 2020 is $1.24 € / \mathrm{L}$ and for 2030 is predicted to be $1.37 € / \mathrm{L}$. The diesel price for the public bus operated by the city should be different from the selling price, but it was calculated assuming that the selling price includes the $\mathrm{M} \& \mathrm{O}$ of the refueling station. Therefore, the $\mathrm{M} \& \mathrm{O}$ cost presented here purely refers to the cost of the bus. 
Table 10. Economical parameters for the diesel bus.

\begin{tabular}{cccc}
\hline Parameter & Value & Unit & Source \\
\hline Vehicle cost & 250,000 & $€$ & {$[56]$} \\
Diesel cost in 2020 & 1.24 & $€ / \mathrm{L}$ & {$[57]$} \\
Diesel cost in 2030 & 1.37 & $€ / \mathrm{L}$ & {$[57]$} \\
Vehicle efficiency & 0.3904 & $\mathrm{~L} / \mathrm{km}$ & {$[58]$} \\
Maintenance and operation cost & 0.25 & $€ / \mathrm{km}$ & {$[59]$} \\
\hline
\end{tabular}

\section{Results and Discussion}

\subsection{Battery Electric Bus}

\subsubsection{Buses Scenario}

The e-Bus TCO for the Offenburg bus lines S5 and S7 carried out an analysis for 2020 and 2030 simultaneously with the $5 \%$ discount rate. As a result, the TCO in 2020 is $2.026 € / \mathrm{km}$ while the TCO in 2030 is $1.279 € / \mathrm{km}$.

In Figure 11, the remarkable difference between 2020 and 2030 is the battery prices. In 2030 , battery prices share drops from $33 \%$ to $7 \%$ according to research trends. Therefore, other factors take up a bigger share position; in particular, bus costs become about half of the total share with $47 \%$. The price of electricity has a larger portion than the price of the battery, which exerts a greater influence on the total cost.

Depot E-Bus in 2020

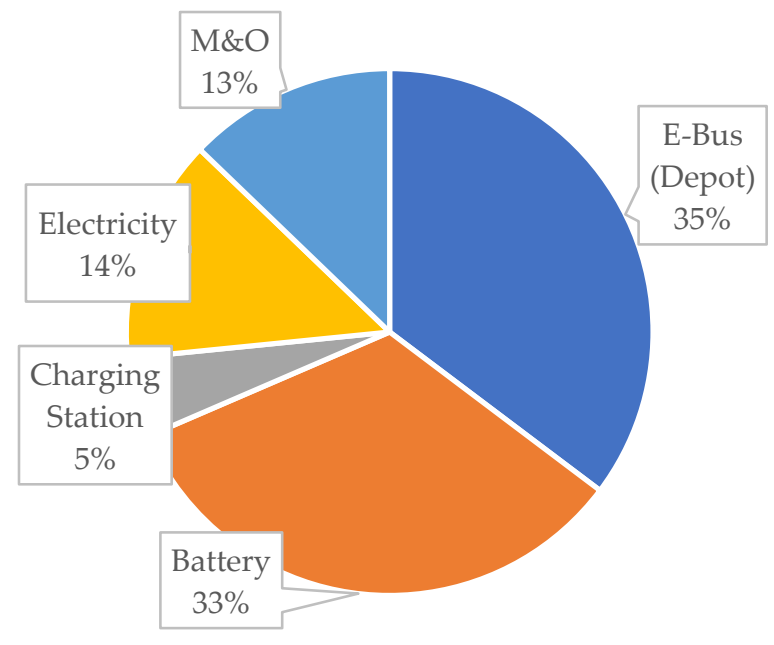

(a)
Depot E-Bus in 2030

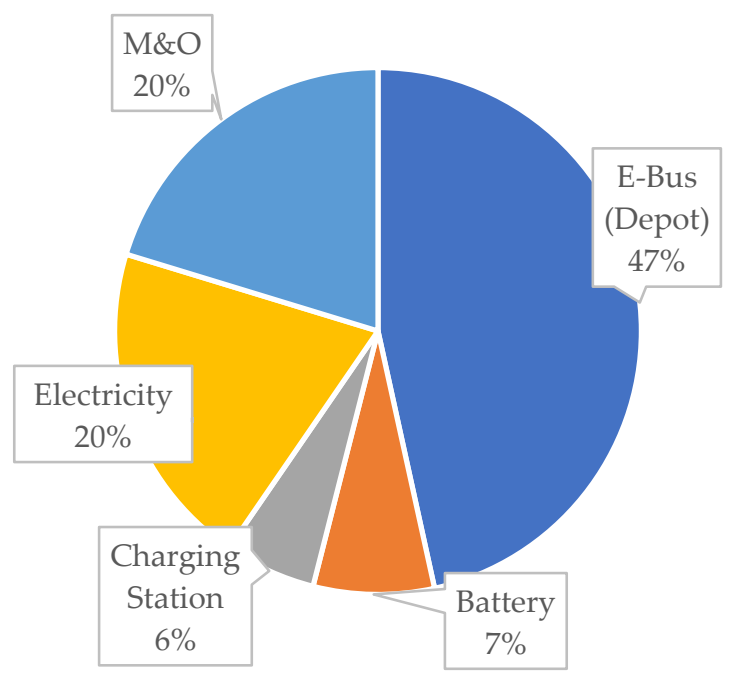

(b)

Figure 11. TCO estimations for battery electric bus with depot charging: (a) in 2020; (b) in 2030.

\subsubsection{Buses Scenario}

Pantograph charging can be used, assuming the city realizes economies of scale through rapid electrification of public buses. The scenario was set with 11 buses that could use one pantograph charging station at the maximum, focusing on the line suitable for the electric bus previously determined, and the result is shown in Figure 12. 


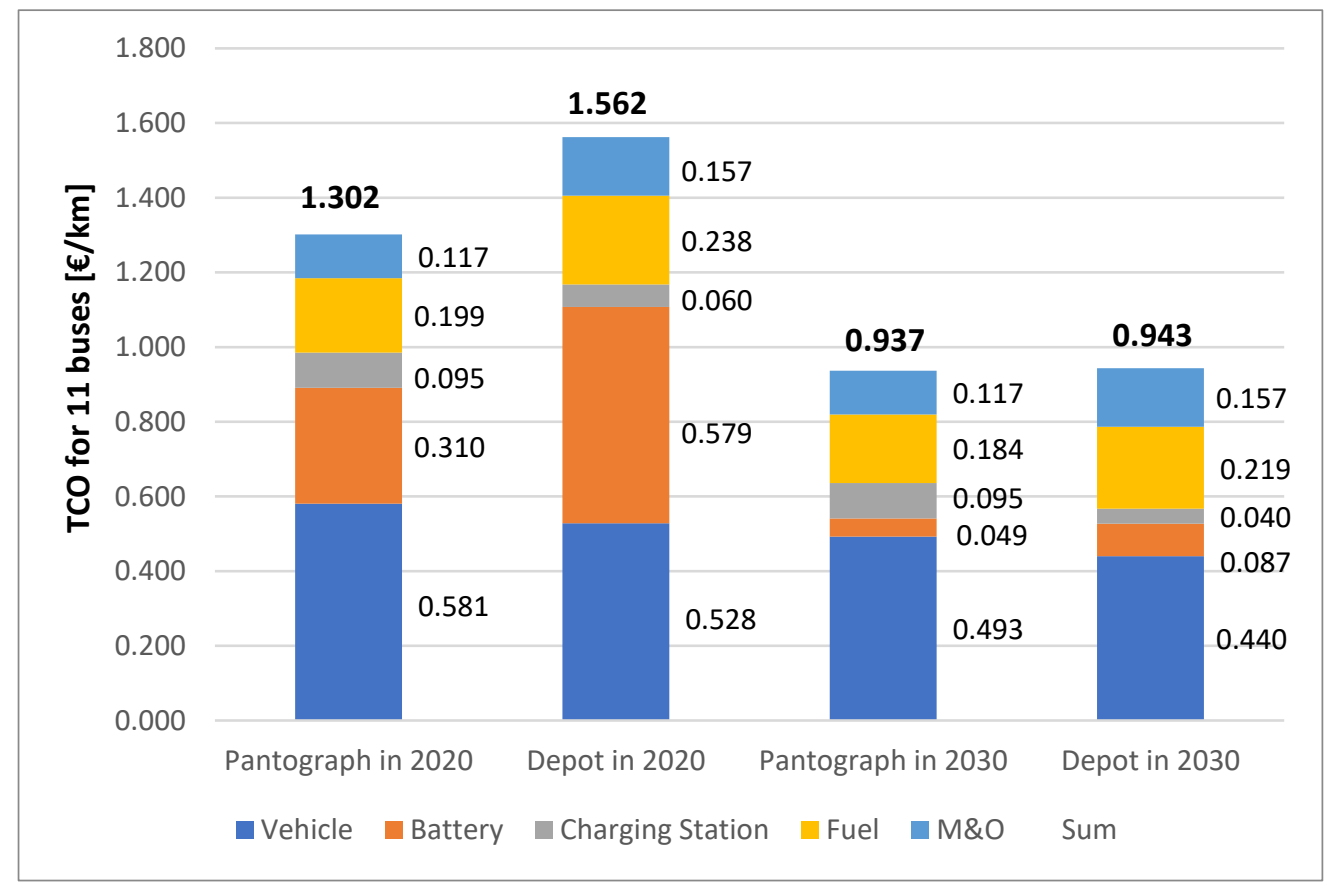

Figure 12. Battery electric bus TCO results for 11 buses scenario with two charging methods.

Figure 12 represents that the pantograph bus scenario is more cost-effective than the depot bus. Although the pantograph bus price is higher than the depot charging bus due to the characteristics of opportunity charging, it requires smaller battery capacities that have lower prices. Additionally, it is possible to cover the route with less electricity, resulting in lower TCO.

In 2020, depot charging has a TCO value that is $0.26 € / \mathrm{km}$ higher than pantograph charging. However, in 2030, the difference between the two models is only $0.005 € / \mathrm{km}$, due to fluctuations in battery prices. The pantograph batteries, which are just needed as a small capacity, save a lot of money as of 2020, but the cost of the battery will be lower in 2030, so the cost-saving effect according to the capacity is not significant.

In other words, it is difficult to determine the advantage of the depot and pantograph models in terms of price based on the TCO results in 2030. However, the pantograph model has more managing and planning aspects, because the lines have to match the pantograph availability. However, it has the advantage, that the vehicles can be charged during the day, which will correspond better to PV feed-in, especially in the future with more renewable energy sources.

\subsection{Hydrogen Fuel Cell Bus}

Data presented in Sections 5.2 and 5.3 serve as inputs for the TCO calculation, overhead and personal costs excluded. As for hydrogen production costs, a discount rate of $5 \%$ was again assumed. TCOs in $€ / \mathrm{km}$ were calculated for the different bus lines both for 2020 and 2030. The TCOs reduction of roughly $30 \%$ for almost each line is mostly due to two factors, the electricity cost reduction and the price drop of the investment costs linked to the $\mathrm{H}_{2}$ technologies, which will strongly depend on their penetration rate into the market. The TCOs computed values are summarized in Table 11. for datasets related to 2020 and Table 12. for dataset related to 2030. Note that for S5/7 and S9, the maintenance costs might be significantly lower as calculated due to the limited mileage driven by the buses for operating these lines. 
Table 11. TCO calculated for dataset related to 2020 .

\begin{tabular}{cccccccc}
\hline & S1/S2 & S3 & S4 & S5/S7 & S6 & S8 & S9 \\
\hline Bus $€ / \mathrm{km}$ & 0.757 & 0.603 & 0.656 & 1.021 & 0.708 & 0.527 & 1.115 \\
FC $€ / \mathrm{km}$ & 0.077 & 0.061 & 0.067 & 0.104 & 0.072 & 0.054 & 0.113 \\
$\mathrm{H}_{2}$ fuel $€ / \mathrm{km}$ & 1.048 & 1.048 & 1.048 & 1.048 & 1.048 & 1.048 & 1.048 \\
M\&O $€ / \mathrm{km}$ & 0.11 & 0.11 & 0.11 & 0.11 & 0.11 & 0.11 & 0.11 \\
TOTAL $€ / \mathrm{km}$ & 1.992 & 1.822 & 1.881 & 2.283 & 1.938 & 1.739 & 2.386 \\
\hline
\end{tabular}

Table 12. TCO calculated for dataset related to 2030 .

\begin{tabular}{cccccccc}
\hline & S1/S2 & S3 & S4 & S5/S7 & S6 & S8 & S9 \\
\hline Bus $€ / \mathrm{km}$ & 0.633 & 0.505 & 0.549 & 0.855 & 0.593 & 0.441 & 0.934 \\
FC $€ / \mathrm{km}$ & 0.061 & 0.049 & 0.053 & 0.083 & 0.058 & 0.043 & 0.091 \\
$\mathrm{H}_{2}$ fuel $€ / \mathrm{km}$ & 0.608 & 0.608 & 0.608 & 0.608 & 0.608 & 0.608 & 0.608 \\
M \&O $€ / \mathrm{km}$ & 0.11 & 0.11 & 0.11 & 0.11 & 0.11 & 0.11 & 0.11 \\
TOTAL $€ / \mathrm{km}$ & 1.412 & 1.272 & 1.32 & 1.656 & 1.369 & 1.202 & 1.743 \\
\hline
\end{tabular}

For both scenarios the different TCOs of each line are strongly influenced by the distance driven per year by each bus. Indeed, the more distance each single bus drives per year, the less bus and FC costs will weight on the TCO.

Nevertheless, the decrease in the TCOs from 2020 to 2030 is mostly due to the reduction in $\mathrm{H}_{2}$ production cost. Figure 13 shows how the costs are split. The results obtained for the line S8 are represented, since it is the line for which the lowest TCO has been obtained for $\mathrm{H}_{2}$ busses. The TCO goes indeed from $1.739 € / \mathrm{km}$ in 2020 to $1.202 € / \mathrm{km}$ in 2030 .
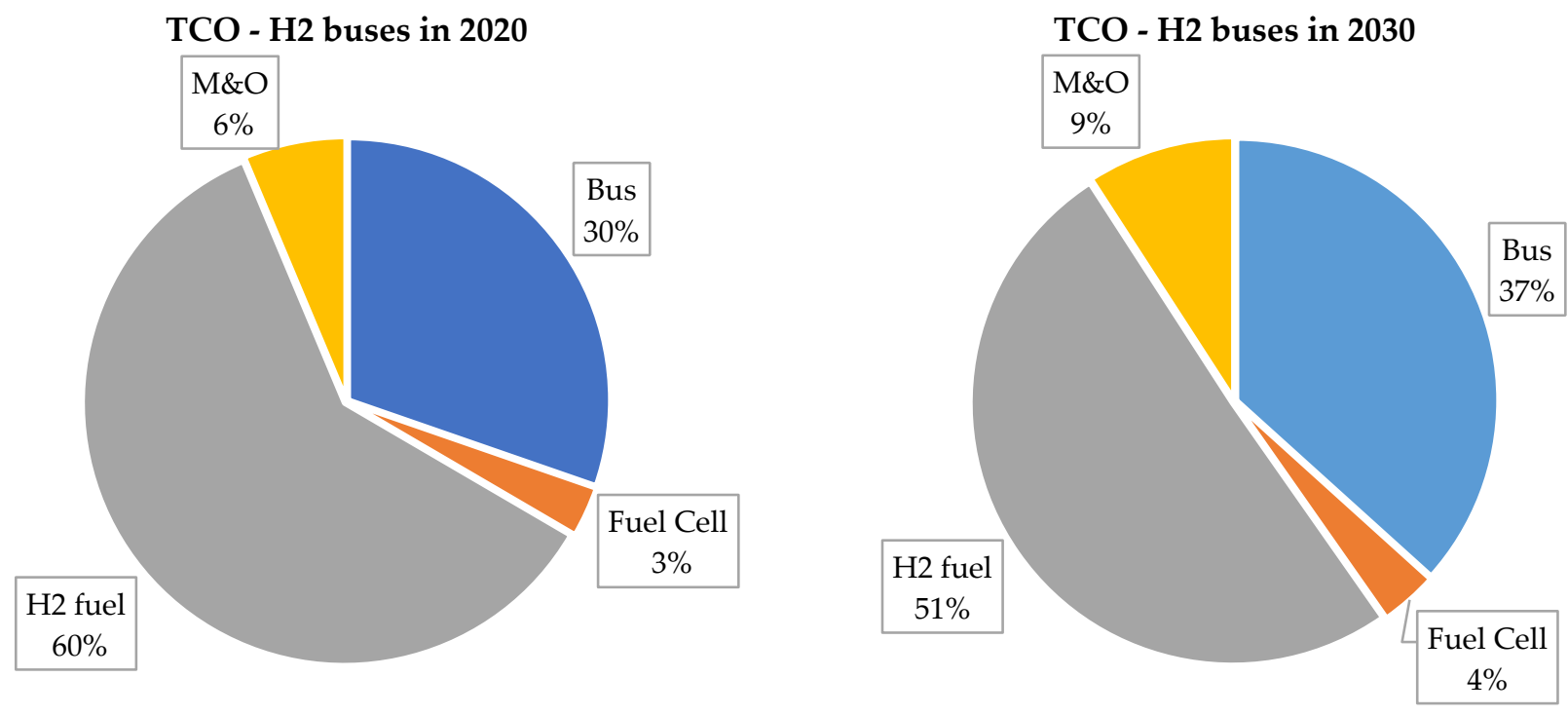

Figure 13. Hydrogen fuel cell bus TCO evolution costs for line S1/S2.

\subsection{Comparison between Electric and Hydrogen Bus}

The scope of the comparison of battery and hydrogen bus solutions with the existing diesel bus fleet has been limited to the inner-city bus system (so called city busses), enabling to consider a captive fleet big enough to legitimate the erecting of a dedicated fueling/charging infrastructure and consisting of busses with homogeneous characteristics. Nevertheless, the further investigation of regional lines could likely reveal patterns making them good candidates for a switch to hydrogen busses, while the implementation of a battery-based solution for those lines might reach some limitations. Hence, the results of this comparative analysis should not be interpreted as an overall statement on the 
competitiveness of one technology against the other, but rather on the suitability of the two investigated solutions for a given network topology and fixed services requirements.

The TCO of the pantograph charging bus in 2020/2030 built up for 11 Offenburg city buses. Figure 14 shows the result of the determined scenarios for the electric, hydrogen and diesel buses.

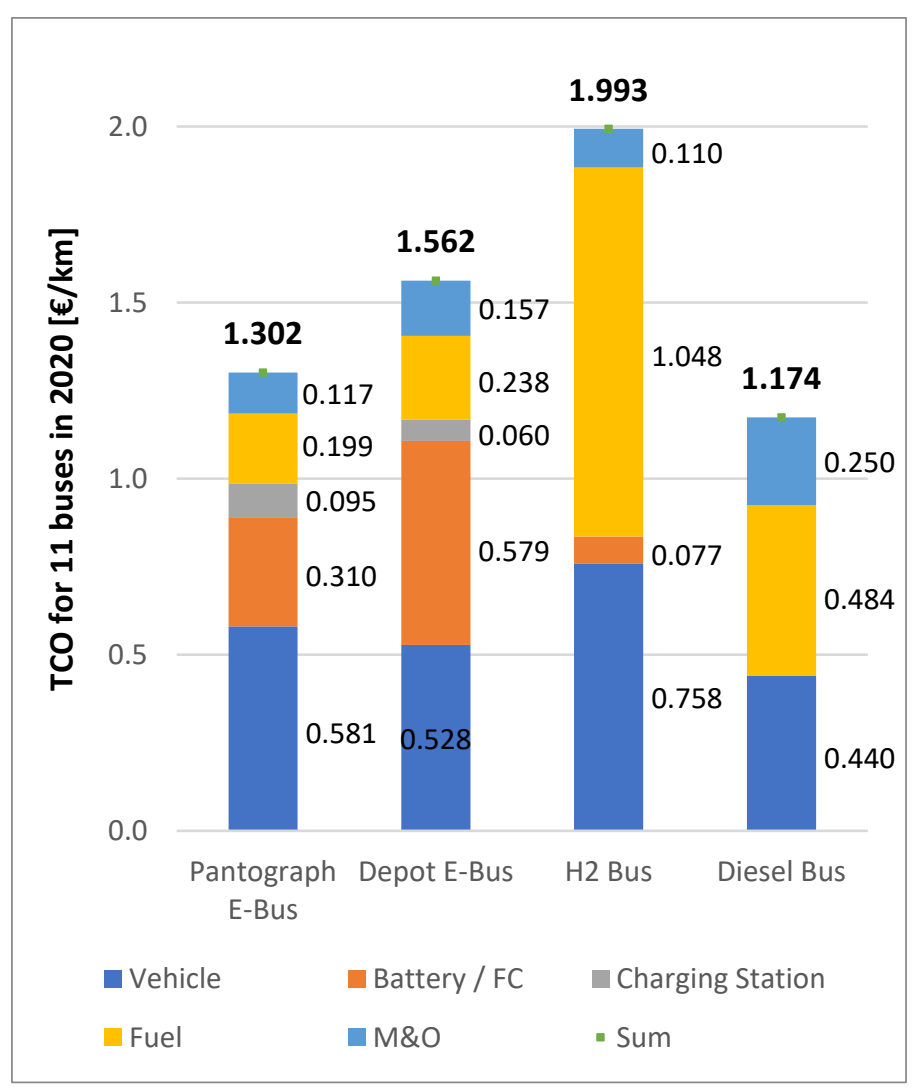

(a)

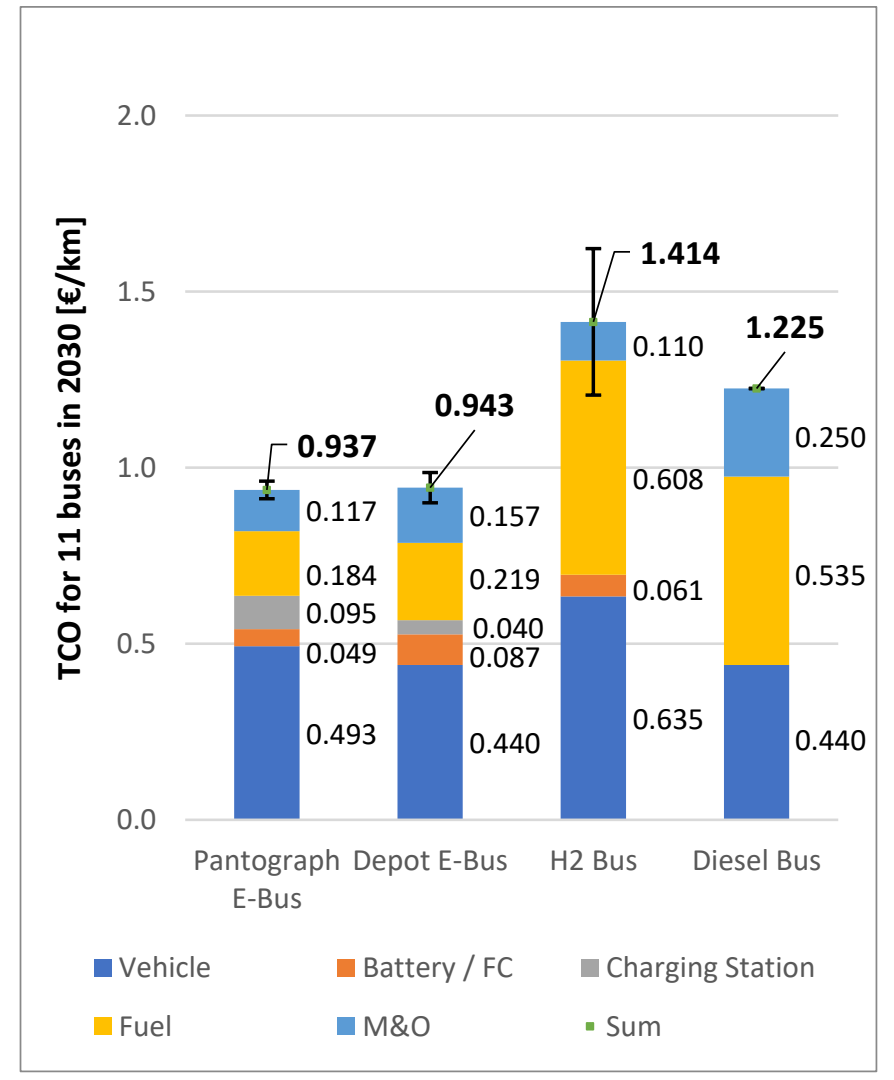

(b)

Figure 14. TCO estimations for 11 buses scenario: (a) in 2020; (b) in 2030 with the sensitivity analysis of battery prices for e-buses and hydrogen costs for fuel cell bus in 2030 results.

In 2030, the pantograph charging bus is the cheapest, followed by depot charging buses, diesel buses, and lastly hydrogen buses. In the pantograph charging scenario, the e-bus cost accounts for the biggest share, followed by electricity prices and $\mathrm{M} \& \mathrm{O}$ costs. Compared with diesel buses, TCO results are as low as $0.288 € / \mathrm{km}$ for the pantograph bus. In 2030, electric buses have a lower TCO than diesel buses are a result of the expected rise in diesel prices and a massive drop in battery prices. The price of the battery is expected to fall to $80 \%$ less than in 2020 , which has the biggest impact on price changes.

However, these results are due to the scenario of using 11 buses that can make the maximum use of the pantograph charging station. Depending on the number of buses, the availability of the charging station will decrease, which increases TCO results.

The results for the $\mathrm{H}_{2}$ bus solution show higher costs compared to all other investigated solutions, notably for the 2020 scenario. The 2030 scenario shows a reduction of the gap between the cost for the conventional diesel solution and the hydrogen solution, despite $20 \%$ additional costs remaining for the hydrogen solution. This cost reduction is mainly achieved by the reduction of CAPEX costs and the reduction of fuel costs achieved by changes in the regulation for electricity consumption.

In addition, the Figure 14b shows the sensitivity analysis based on the 2030 model. It gives an overview of how the values of the TCO model can change as the values of various variables change. Variables to which price fluctuations are applied are battery 
prices for electric buses and hydrogen costs for fuel cell buses, and the range of each price is determined by the minimum and maximum values based on past data and future forecasts (Table 13).

Table 13. Sensitivity analysis of battery prices for e-buses and hydrogen costs for fuel cell bus in 2030 results.

\begin{tabular}{cccc}
\hline Parameter & $\begin{array}{c}\text { Battery Prices } \\
\text { for Depot Buses } \\
{[\boldsymbol{\epsilon} / \mathbf{k W h}]}\end{array}$ & $\begin{array}{c}\text { Battery Prices for } \\
\text { Pantograph Buses } \\
{[\boldsymbol{\epsilon} / \mathbf{k W h}]}\end{array}$ & $\begin{array}{c}\text { Hydrogen Costs for } \\
\text { Pantograph Buses } \\
{[\boldsymbol{\epsilon} / \mathbf{k g}]}\end{array}$ \\
\hline Optimistic & 50 & 100 & 5 \\
Base & 100 & 200 & 7.6 \\
Pessimistic & 150 & 300 & 10.2 \\
\hline
\end{tabular}

Changes in battery prices in 2030 do not have a significant impact on electric bus TCO results. Since it has already been predicted that the battery price will fall significantly compared to 2020 , the price fluctuation at the declined price is not large within the total TCO in 2030.

However, for the hydrogen bus scenario, the benefits of a hypothetical scaling-up effect of hydrogen infrastructures in the region are driven by additional demand beside the Offenburg city bus system. The hydrogen cost as a result could drop to $5 € / \mathrm{kg}$. In this case, the overall TCO of the hydrogen solution would drop to $1.206 € / \mathrm{km}$, which is lower than the TCO for the diesel solution in 2030. In this case, the cost parity is achieved also for the fuel cell bus. This technology switch would still have no impact on operations and still allow full routes flexibility in the long term.

Additionally, more sensitivity analysis was performed based on the pantograph scenario model which has the best results in 2030. It gives an overview of how the values of the TCO model can change as the values of various variables change. Variables to which price fluctuations are applied are price and lifetime of bus and battery, and the range of each value is determined by the minimum and maximum values based on past data and future forecasts (Tables 13 and 14).

Table 14. Sensitivity analysis of price and lifetime of bus and battery based on the result of pantograph model in 2030.

\begin{tabular}{cccc}
\hline Parameter & $\begin{array}{c}\text { Vehicle Body Prices } \\
{[\mathbf{k} \boldsymbol{\epsilon}]}\end{array}$ & $\begin{array}{c}\text { Lifetime of a Vehicle } \\
\text { Body [Year] }\end{array}$ & $\begin{array}{c}\text { Lifetime of a Battery } \\
\text { [Year] }\end{array}$ \\
\hline Optimistic & 196 & 15.6 & 9.75 \\
Base & 280 & 12 & 6.5 \\
Pessimistic & 364 & 8.4 & 3.25 \\
\hline
\end{tabular}

Changes in bus and battery prices also have a major impact on TCO electric buses. While the price of the battery changes from $200 € / \mathrm{kWh}$ to $300 € / \mathrm{kWh}$ from $50 \%$ to $150 \%$, the bus has a narrow price range of $70-130 \%$, from a minimum of $364,000 €$ to $196,000 €$.

The lifetime of buses and batteries are also key variables in the TCO model. According to actual market research, e-bus can be used under proper management for up to 20 years. The battery is also estimated to take 10 years to its nominal capacity falls below $80 \%$ of its initial rated capacity. These increases in lifespan result in lowering the TCO.

Figure 15 shows the change in TCO result according to the change in lifetimes and prices of the model. The induced change in the e-bus TCO is expected to drop and increase by $0.148 € / \mathrm{km}$ with the bus price changes. In the battery, a decrease, and an increase of up to $0.024 € / \mathrm{km}$ have less impact on the TCO than the bus, although the battery has even a rather big price range. 


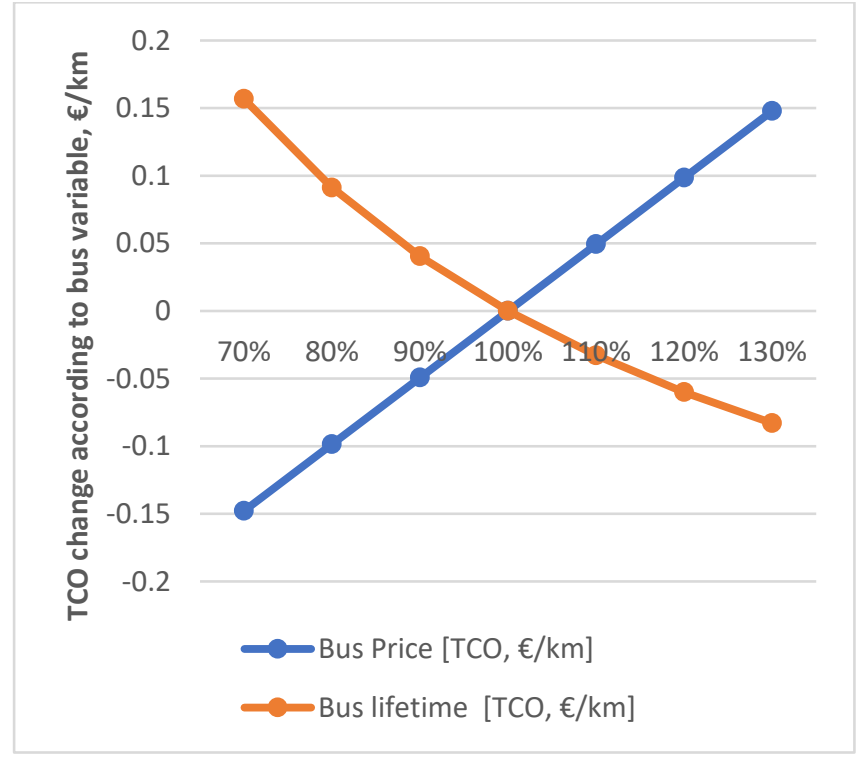

(a)

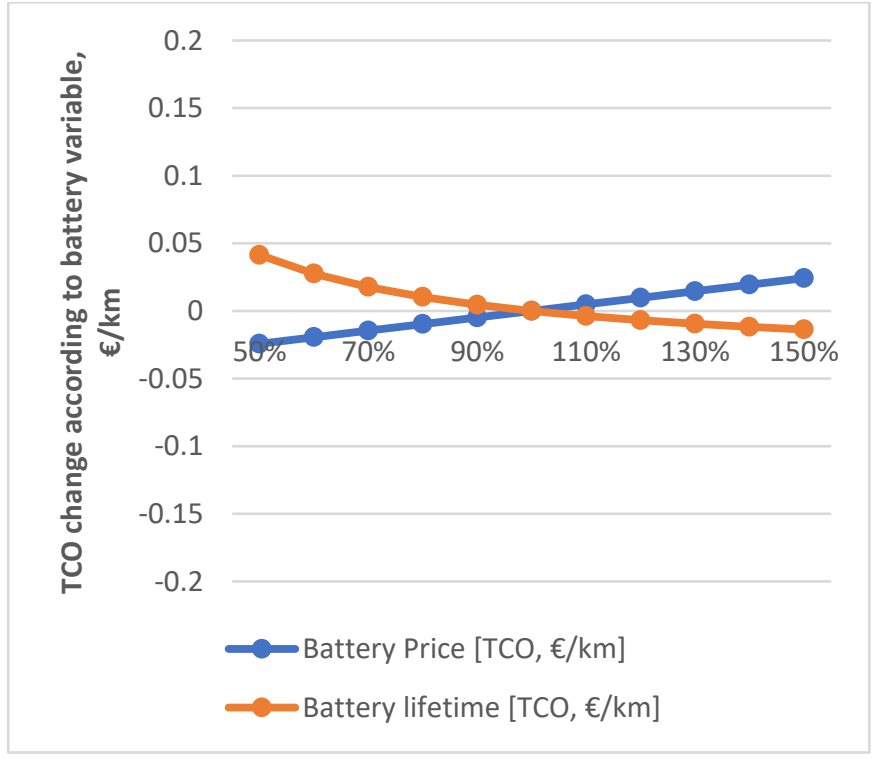

(b)

Figure 15. Sensitivity analysis in 2030 results: (a) vehicle body price and lifetime of e-buses; (b) battery prices and lifetime.

The result of TCO fluctuates also as the life expectancy of each e-bus and battery increases. As the lifetime value increases, the TCO value decreases, so that, unlike the previous price change graphs, the decline curve is drawn. The differences in e-bus lifetimes affect more strongly TCO results than the other parameter because the price of the bus is accounting for the biggest part as $47 \%$ of the total result from the pantograph charging scenario in 2030. The lifetime sensitivity results of the battery do not cause a significant change in the total TCO, because $7 \%$ accounts for a small portion of the result.

\section{Conclusions and Outlook}

Consequently, the TCO models can be used in finding economical solutions for a full emission-free bus introduction into the public transport system. In the study, the depot and pantograph charging electric bus, and hydrogen bus models were compared with the diesel bus TCO. The results indicate that the short-range fully electric bus scenario with shared opportunity charging infrastructure is the most economical solution in 2030.

However, the pantograph charging method is applicable under the assumption that several buses share the same station. In Offenburg's case, all 11 buses stop in front of the train station, so there was no difficulty in selecting the location of the Pantograph charging station. Therefore, for the analysis of other cities, finding a bus station where a certain number of buses gather acts as an important key factor.

On the other hand, the $\mathrm{H}_{2}$ solution, while showing greater flexibility and having less impact on current operations remains significantly impacted by higher CAPEX and fuel costs for the current time. If the expected cost reduction targets are achieved in the next decade, the main driver for the competitiveness of hydrogen solution would be the fuel costs. A TCO parity with the diesel solution is reachable under the assumption of large-scale hydrogen infrastructure, leading to decreased fuel costs making benefit of economies of scale, while possibly serving different uses in the region, hence contributing to decarbonize different sectors or applications. In the considered use case, the utilization rate of the buses remains moderate in overall. Extending the use case to the operation of hydrogen busses on the existing regional lines would possibly further highlight the advantages of strength of the hydrogen solution in an integrated regional approach.

The main advantage of $\mathrm{H}_{2}$ buses is that they have a similar range to the diesel one as well as a similar refueling time. That brings to an easier logistic approach, making possible 
the substitution of 1 diesel bus with $1 \mathrm{H}_{2}$ bus, almost regardless to the topology of the considered network/line.

The positive survey results of Offenburg citizens' acceptance of hydrogen buses (Figure 4) motivate the study and suggest that the city is ready for change. Based on their increased requirements of emission-free buses, a bold decision of the city is needed to get started with this revolutionary change in public transport.

This study is also related to other small to midsize cities, as these generally have similar public bus lines and schedules. These public bus lines in small to midsize cities will gradually increase economic competitiveness with alternative powertrains compared with existing diesel buses.

Research can continue to support this transformation by taking into account the complex relationships in public transport, and to make alternative powertrain city bus transport a sustainable reality. Such a transformation necessitates changes in the value chain of public transport with considerations of new business models, new traffic system designs, and operations.

Author Contributions: Conceptualization, H.K., N.H. and M.Z.; methodology, H.K.; software, H.K.; validation, H.K., N.H. and M.Z.; formal analysis, H.K. and N.H.; investigation, H.K., N.H., M.Z., R.L. and T.S.; resources, H.K., N.H., M.Z., R.L. and T.S.; data curation, H.K., N.H., M.Z., R.L. and T.S.; writing—original draft preparation, H.K., N.H., M.Z., R.L. and T.S.; writing-review and editing, H.K. and N.H.; visualization, H.K.; supervision, N.H.; project administration, M.Z and N.H.; funding acquisition, M.Z. and N.H. All authors have read and agreed to the published version of the manuscript.

Funding: This research was funded by the Ministry of the Environment, Climate and Energy Economics in the State of Baden-Württemberg within the frame of the "H2-BUS Offenburg" project, grant number BWÖPN 18006. The article processing charge was funded by the Baden-Württemberg Ministry of Science, Research and Culture and the Offenburg University of Applied Sciences in the funding program Open Access Publishing.

Institutional Review Board Statement: Not applicable.

Informed Consent Statement: Informed consent was obtained from all subjects involved in the study.

Data Availability Statement: Not applicable.

Conflicts of Interest: The authors declare no conflict of interest.

\section{Appendix A}

Structure analysis for bus lines in Offenburg: the city bus lines (Table A1, S1 to S9) and the regional lines (R106, R301) would be recommended for operation with hydrogen and battery-electric vehicles. 
Table A1. Structure analysis for bus lines in Offenburg: the city bus lines (S1 to S9) and the regional lines (R106, R301).

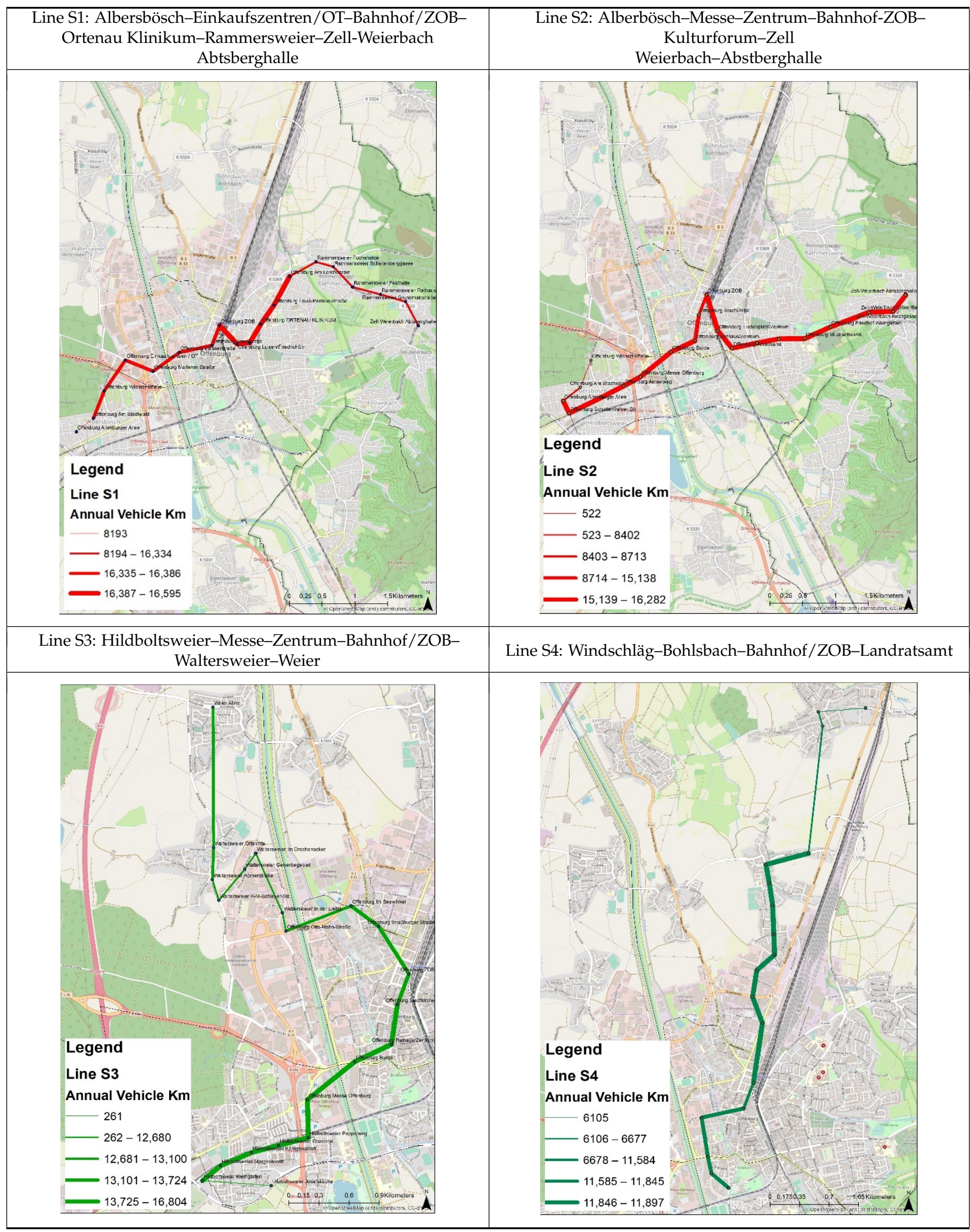


Table A1. Cont.

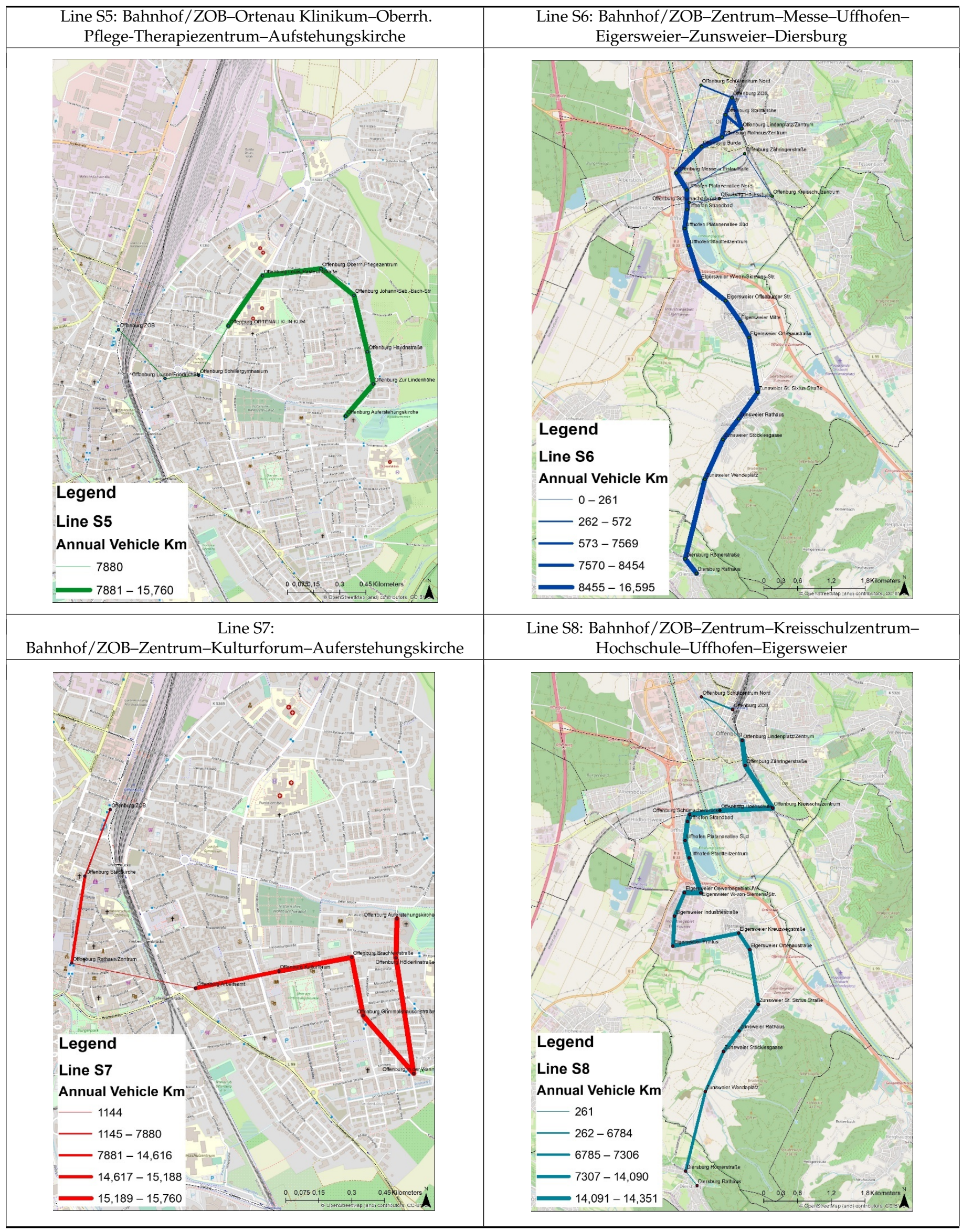


Table A1. Cont.

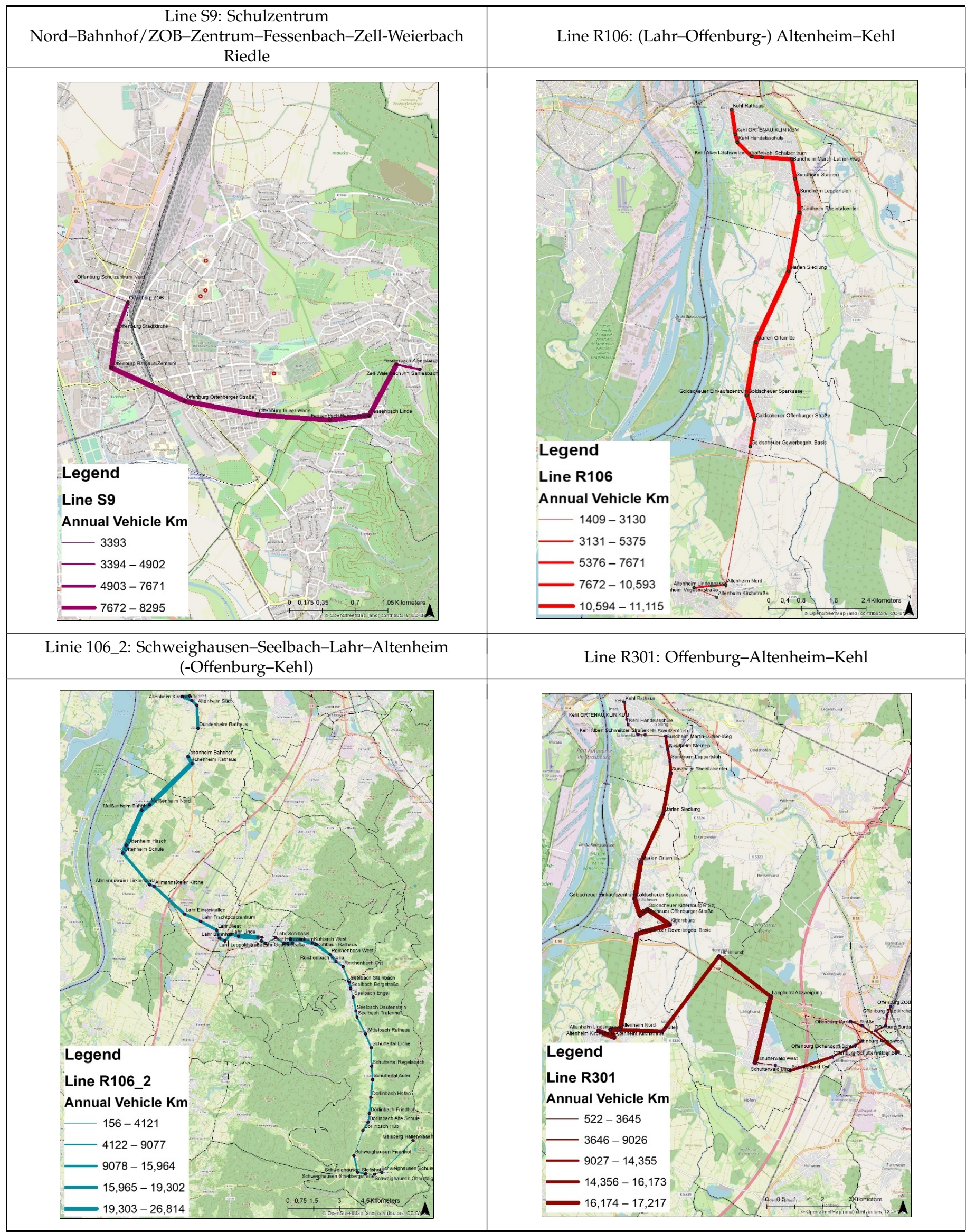




\section{References}

1. Kunith, A.; Mendelevitch, R.; Goehlich, D. Electrification of a city bus network-An optimization model for cost-effective placing of charging infrastructure and battery sizing of fast-charging electric bus systems. Int. J. Sustain. Transp. 2017, 11, 707-720. [CrossRef]

2. ZeEUS. ZeEUS eBus Report-An Overview of Electric Buses in Europe. Available online: https://zeeus.eu/uploads/ publications / documents / zeeus-ebus-report-internet.pdf (accessed on 14 April 2019).

3. Offer, G.J.; Howey, D.; Contestabile, M.; Clague, R.; Brandon, N.P. Comparative analysis of battery electric, hydrogen fuel cell and hybrid vehicles in a future sustainable road transport system. Energy Policy 2010, 38, 24-29. [CrossRef]

4. Lozanovski, A.; Whitehouse, N.; Ko, N.; Whitehouse, S. Sustainability Assessment of Fuel Cell Buses in Public Transport. Sustainability 2018, 10, 1480. [CrossRef]

5. Quarles, N.; Kockelman, K.M.; Mohamed, M. Costs and Benefits of Electrifying and Automating Bus Transit Fleets. Sustainability 2020, 12, 3977. [CrossRef]

6. Brdulak, A.; Chaberek, G.; Jagodziński, J. Development Forecasts for the Zero-Emission Bus Fleet in Servicing Public Transport in Chosen EU Member Countries. Energies 2020, 13, 4239. [CrossRef]

7. Yan, Y.; Wang, H.; Jiang, J.; Zhang, W.; Bao, Y.; Huang, M. Research on Configuration Methods of Battery Energy Storage System for Pure Electric Bus Fast Charging Station. Energies 2019, 12, 558. [CrossRef]

8. Chen, G.; Hu, D.; Chien, S.; Guo, L.; Liu, M. Optimizing Wireless Charging Locations for Battery Electric Bus Transit with a Genetic Algorithm. Sustainability 2020, 12, 8971. [CrossRef]

9. Połom, M.; Wiśniewski, P. Implementing Electromobility in Public Transport in Poland in 1990-2020. A Review of Experiences and Evaluation of the Current Development Directions. Sustainability 2021, 13, 4009. [CrossRef]

10. Ammenberg, J.; Dahlgren, S. Sustainability Assessment of Public Transport, Part I-A Multi-Criteria Assessment Method to Compare Different Bus Technologies. Sustainability 2021, 13, 825. [CrossRef]

11. Barraza, O.; Estrada, M. Battery Electric Bus Network: Efficient Design and Cost Comparison of Different Powertrains. Sustainability 2021, 13, 4745. [CrossRef]

12. Díez, A.; Restrepo, M. A Planning Method for Partially Grid-Connected Bus Rapid Transit Systems Operating with In-Motion Charging Batteries. Energies 2021, 14, 2550. [CrossRef]

13. Kivekäs, K.; Lajunen, A.; Vepsäläinen, J.; Tammi, K. City Bus Powertrain Comparison: Driving Cycle Variation and Passenger Load Sensitivity Analysis. Energies 2018, 11, 1755. [CrossRef]

14. Choi, U.-D.; Jeong, H.-K.; Jeong, S.-K. Commercial operation of ultra low floor electric bus for Seoul city route. In Proceedings of the IEEE Vehicle Power and Propulsion Conference (VPPC), Seoul, Korea, 9-12 October 2012.

15. Lajunen, A. Energy consumption and cost-benefit analysis of hybrid and electric city buses. Transp. Res. Part C: Emerg. Technol. 2014, 38, 1-15. [CrossRef]

16. Stempien, J.; Chan, S.; Stempien, J.; Chan, S. Comparative study of fuel cell, battery and hybrid buses for renewable energy constrained areas. J. Power Sources 2017, 340, 347-355. [CrossRef]

17. Ajanovic, A.; Haas, R.; Ajanovic, A.; Haas, R. Prospects and impediments for hydrogen and fuel cell vehicles in the transport sector. Int. J. Hydrogen Energy 2021, 46, 10049-10058. [CrossRef]

18. Meishner, F.; Sauer, D.U. Introduction of Battery Electric Buses in European Cities. In Proceedings of the 7th Transport Research Arena TRA 2018, Vienna, Austria, 16-19 April 2018.

19. Nurhadi, L.; Borén, S.; Ny, H. A Sensitivity Analysis of Total Cost of Ownership for Electric Public Bus Transport Systems in Swedish Medium Sized Cities. Transp. Res. Procedia 2014, 3, 818-827. [CrossRef]

20. Pihlatie, M.; Kukkonen, S.; Halmeaho, T.; Karvonen, V.; Nylund, N.-O. Fully Electric City Buses-The Viable Option. In Proceedings of the 2014 IEEE International Electric Vehicle Conference (IEVC), Florence, Italy, 17-19 December 2014.

21. Vepsäläinen, J.; Baldi, F.; Lajunen, A.; Kivekäs, K.; Tammi, K. Cost-Benefit Analysis of Electric Bus Fleet with Various Oper-ation Intervals. In Proceedings of the 21st International Conference on Intelligent Transportation Systems (ITSC), Maui, HI, USA, 4-7 November 2018.

22. Wang, G.; Xie, X.; Zhang, F.; Liu, Y.; Zhang, D. bCharge: Data-Driven Real-Time Charging Scheduling for Large-Scale Electric Bus Fleets. In Proceedings of the 2018 IEEE Real-Time Systems Symposium (RTSS), Nashville, TE, USA, 11-14 December 2018; pp. 45-55. [CrossRef]

23. Briñas Gorosabel, O.L. Assessing the Construction of Charging Stations for Electric Buses-A Case Study for Stockholm Inner City. Master's Thesis, KTH Royal Institute of Technology, Stockholm, Sweden, 2017.

24. Babin, A.; Rizoug, N.; Mesbahi, T.; Boscher, D.; Hamdoun, Z.; Larouci, C. Total Cost of Ownership Improvement of Commercial Electric Vehicles Using Battery Sizing and Intelligent Charge Method. IEEE Trans. Ind. Appl. 2018, 54, 1691-1700. [CrossRef]

25. FCH-JU. Urban Buses: Alternative Powertrains for Europe. Available online: https://www.fch.europa.eu/sites/default/files/20 121029\%20Urban\%20buses\%2C\%20alternative\%20powertrains\%20for\%20Europe\%20-\%20Final\%20report_0_0.pdf (accessed on 30 June 2019).

26. Bundesministerium für Verkehr und digitale Infrastruktur BMVI (2008): Mobilität in Deutschland (MiD). 2008. Available online: https:/ / www.bmvi.de/SharedDocs/DE/Artikel/G/mobilitaet-in-deutschland.html (accessed on 30 June 2019).

27. DELFI e.V. (2018): Zentrales Haltestellenverzeichnis-zHV. Hg. v. WVI Prof. Dr. Wermuth Verkehrsforschung und Infrastrukturplanung GmbH. Available online: https:/ / zhv.wvigmbh.de/ (accessed on 19 April 2021). 
28. VALIDATE. Karlsruhe: PTV Group. Available online: https://www.ptvgroup.com/de/loesungen/produkte/ptv-karten-daten/ verkehrsplanung/validate/ (accessed on 18 April 2021).

29. Bloomberg New Energy Finance: Electric Buses in Cities: Driving towards Cleaner Air and Lower $\mathrm{CO}_{2}$. 2018. Available online: https:/ / about.bnef.com/blog/electric-buses-cities-driving-towards-cleaner-air-lower-co2/ (accessed on 5 July 2019).

30. Kunith, A.W. Elektrifizierung des Urbanen Öffentlichen Busverkehrs; Springer: Wiesbaden, Germany, 2017; p. 146.

31. Mathieu, L. Electric Buses Arrive on Time. Available online: https:/ /www.transportenvironment.org/sites/te/files/publications/ Electric\%20buses\%20arrive\%20on\%20time.pdf (accessed on 5 July 2019).

32. Grütter, J.M. Real World Performance of Hybrid and Electric Buses; Grütter Consulting AG: Reinach, Switzerland, 2015.

33. Mohamed, M.; Higgins, C.; Ferguson, M.; Requia, W. The influence of vehicle body type in shaping behavioural intention to acquire electric vehicles: A multi-group structural equation approach. Transp. Res. Part A Policy Pract. 2018, 116, 54-72. [CrossRef]

34. Eudy, L.; Prohaska, R.; Kelly, K.; Post, M. Foothill Transit Battery Electric Bus Demonstration Results. National Renewable Energy Laboratory, Jan. 2016. Available online: https://www.nrel.gov/docs/fy16osti/65274.pdf (accessed on 5 July 2019).

35. Maria, Ö. Information om Genomförd Behovsanalys av Övergång till Eldriven Busstrafik 2015. Available online: https:/ / docplayer. se/788872-Information-om-genomford-behovsanalys-av-overgang-till-eldriven-busstrafik.html (accessed on 16 July 2019).

36. Lajunen, A.; Lipman, T. Lifecycle cost assessment and carbon dioxide emissions of diesel, natural gas, hybrid electric, fuel cell hybrid and electric transit buses. Energy 2016, 106, 329-342. [CrossRef]

37. Hoerold, S.; Breitkopf, M. Städteübergreifendes Konzept für Elektrisch Angetriebene Busse in Theringer Mittelstaedten; Fraunhofer IVI: Dresden, Germany, 2015.

38. Nykvist, B.; Sprei, F.; Nilsson, M. Assessing the progress toward lower priced long range battery electric vehicles. Energy Policy 2019, 124, 144-155. [CrossRef]

39. Bus2bus, e-Buses: Manufacturers Are Delivering. Available online: https://www.bus2bus.berlin/en/blog/e-busesmanufacturers-are-delivering/ (accessed on 16 July 2019).

40. Oeko-Institut. Projected EEG Costs up to 2035. A Study Commissioned by Agora Energiewende. 2016. Available online: https:// static.agora-energiewende.de/fileadmin/Projekte/2015/EEG-Kosten-bis-2035/Agora_EEG-Kosten_bis_2035_EN_WEB.pdf (accessed on 16 July 2019).

41. International Energy Agency. Global EV Outlook 2018. Available online: https://www.connaissancedesenergies.org/sites/ default/ files/pdf-actualites/globalevoutlook2018.pdf (accessed on 16 July 2019).

42. Potkány, M.; Technical University in Zvolen Faculty of Wood Sciences and Technology Department of Business Economics Slovak Republic; Hlatká, M.; Debnár, M.; Hanzl, J. Comparison of the Lifecycle Cost Structure of Electric and Diesel Buses. Naše More 2018, 65, 270-275. [CrossRef]

43. Rendimiento Real de Buses. Available online: https://www.yutong.com/products/E12\%EF\%BC\%88ZK6128BEVG\%EF\%BC\%89 -EuropeNA.shtml (accessed on 16 July 2019).

44. Barnitt, R. NREL Case Study: Ebus Hybrid Electric Buses and Trolleys. Technical Report, July 2006. Available online: https: // www.nrel.gov / docs / fy06osti/38749.pdf (accessed on 10 July 2020).

45. Laver, R.; Schneck, D.; Skorupski, D.; Brady, S.; Cham, L.; Hamilton, B.A. Useful Life of Transit Buses and Vans. Federal Transit Administration. Springfield, U.S. April 2007. Available online: https://www.transitwiki.org/TransitWiki/images/6/64/Useful_ Life_of_Buses.pdf (accessed on 9 August 2020).

46. Vilppo, O.; Markkula, J. Feasibility of Electric Buses in Public Transport. World Electr. Veh. J. 2015, 7, 357-365. [CrossRef]

47. Regional Transportation Commission of Washoe County. Electric Bus Initiative Benefit-Cost Analysis Supplementary Documentation. TIGER Discretionary Grant Program. 29 April 2016. Available online: https:/ /www.rtcwashoe.com/wp-content/uploads / 2017/04/2016-Tiger-Grant-BCA.pdf (accessed on 29 September 2020).

48. Conti, V.; Orchi, S.; Valentini, M.P.; Nigro, M.; Calò, R. Design and evaluation of electric solutions for public transport. Transp. Res. Procedia 2017, 27, 117-124. [CrossRef]

49. Johnson, C.; Nobler, E.; Eudy, L.; Jeffers, M. Financial Analysis of Battery Electric Transit Buses; National Renewable Energy Laboratory: Golden, CO, USA, 2020.

50. NREL/TP-5400-74832. Available online: https://www.nrel.gov/docs/fy20osti/74832.pdf (accessed on 23 October 2020).

51. EMCEL. Wie Entwickeln Sich Die Preise für Brennstoffzellenbusse? EMCEL. 2018. Available online: https://emcel.com/de/ preise-fuer-brennstoffzellenbusse/ (accessed on 5 March 2021).

52. Berger, R. Fuel Cell Electric Buses_Potential for Sustainable Public Transport in Europe; FCH-JU: Munchen, Germany, 2015.

53. Element Energy Limited. Strategies for Joint Procurement of Fuel Cell Buses; FCH-JU: Munchen, Germany, 2018. Available online: https:/ / www.fch.europa.eu/sites /default/files/Strategies_\%20for_joint_procurement_of_FCbuses_final_report.pdf (accessed on 5 March 2021).

54. Torregrossa, M. UGAP: Une Commande Groupée pour 1000 Bus à Hydrogène d'ici 2024, 2019. Available online: https:/ /www.h2 -mobile.fr/actus/ugap-commande-groupee-1000-bus-hydrogene-2024/ (accessed on 10 March 2021).

55. Reuter, D.B. New Bus ReFuelling for European Hydrogen Bus Depots. FCH JU. 2017. Available online: http:/ / newbusfuel.eu/ wp-content/uploads/2017/03/NewBusFuel_D4.3_Guidance-document-for-large-scale-hydrogen-refuelling_final.pdf (accessed on 10 March 2021). 
56. Ballard. FUEL CELL ELECTRIC BUSES, Proven Performance and the Way Forward. 2019. Available online: https:/ /www.ballard. com/docs/default-source/web-pdf's/white-paper_fuel-cell-buses-for-france_final-english-web.pdf?sfvrsn=939bc280_0 (accessed on 16 March 2021).

57. Lajunen, A.; Tammi, K. Evaluation of Energy Consumption and Carbon Dioxide Emissions of Electric City Buses; Electric Commercial Vehicles (ECV); VTT Technical Research Centre of Finland: Espoo, Finland, 2019; pp. 104-120.

58. Hacker, F.; Waldenfels, R.; Mottschall, M. Wirtschaftlichkeit von Elektromobilität in gewerblichen Anwendungen: Betrachtung von Gesamtnutzungskosten, ökonomischen Potenzialen und möglicher CO2-Minderung. IKT für Elektromo-bilität, Berlin, Germany, April 2015. Available online: https:/ /www.digitale-technologien.de/DT/Redaktion/DE/Downloads/Publikation/ IKT-EM/ikt2-studie-wirtschaftlichkeit-ikt-elektromobilitaet-2.pdf?_blob=publicationFile\&v=4 (accessed on 20 March 2021).

59. Energy Efficiency in Transport from Wikipedia. Available online: https://en.wikipedia.org/wiki/Energy_efficiency_in_ transport\#Buses (accessed on 20 March 2020). 